\title{
Heat and Mass Transfer Analysis of a Desiccant Dehumidifier Matrix
}

A. A. Pesaran

July 1986

Prepared under Task No. 3009.10

FTP No. $467-84$

Solar Energy Research Institute

A Division of Midwest Research Institute

1617 Cole Boulevard

Golden, Colorado 80401

Prepared for the

U.S. Department of Energy

Contract No. DE-AC02-83CH10093 


\section{NOTICE}

This report was prepared as an account of work sponsored by the United States Government. Neither the United States nor the United States Department of Energy, nor any of their employees, nor any of their contractors, subcontractors, or their employees, makes any warranty, expressed or implied, or assumes any legal liability or responsibility for the accuracy, completeness or usefulness of any information. apparatus, product or process disclosed, or represents that its use would not infringe privately owned rights.

\section{Printed in the United States of America \\ Available from: \\ National Technical Information Service}

U.S. Department of Commerce

5285 Port Royal Road

Springfield, VA 22161

Price: Microfiche A01

Printed Copy AO4

Codes are used for pricing all publications. The code is determined by the number of pages in the publication. Information pertaining to the pricing codes can be found in the current issue of the following publications, which are generally available in most libraries: Energy Research Abstracts, (ERA); Government Reports Announcements and Index (GRA and I); Scientific and Technical Abstract Reports (STAR); and publication, NTIS-PR-360 available from NTIS at the above address. 
PREFACE

In keeping with the national energy policy goal of fostering an adequate supply of energy at a reasonable cost, the United States Department of Energy (DOE) supports a variety of programs to promote a balanced and mixed energy resource system. The mission of the DOE Solar Buildings Research and Development Program is to support this goal by providing for the development of solar technology alternatives for the buildings sector. It is the goal of the program to establish a proven technology base to allow industry to develop solar products and designs for buildings that are economically competitive and can contribute significantly to the nation's building energy supplies. Toward this end, the program sponsors research activities related to increasing the efficiency, reducing the cost, and improving the long-term durability of passive and active solar systems for building water and space heating, cooling, and daylighting applications. These activities are conducted in four major areas: Advanced Passive Solar Materials Research, Collector Technology Research, Cooling Systems Research, and Systems Analysis and Applications Research.

Advanced Passive Solar Materials Research - This activity area includes work on new aperture materials for controlling solar heat gains, and for enhancing the use of daylight for building interior lighting purposes. It also encompasses work on low-cost thermal storage materials that have high thermal storage capacity and can be integrated with conventional building elements, and work on materials and methods to transport thermal energy efficiently between any building exterior surface and the building interior by nonmechanical means.

Collector Technology Research - This activity area encompasses work on advanced low- to medium-temperature (up to $180^{\circ} \mathrm{F}$ useful operating temperature) flat-plate collectors for water and space heating applications, and medium- to high-temperature (up to $400^{\circ} \mathrm{F}$ useful operating temperature) evacuated tube/concentrating collectors for space heating and cooling applications. The focus is on design innovations using new materials and fabrication techniques.

Cooling Systems Research - This activity area involves research on highperformance dehumidifiers and chillers that can operate efficiently with the variable thermal outputs and delivery temperatures associated with solar collectors. It also includes work on advanced passive cooling techniques.

Systems Analysis and Applications Research - This activity area encompasses experimental testing, analysis, and evaluation of solar heating, cooling, and daylighting systems for residential and nonresidential buildings. This involves system integration studies, the development of design and analysis tools, and the establishment of overall cost, performance, and durability targets for various technology or system options.

This report is an account of research conducted in cooling system research to improve the performance of solid desiccant dehumidifiers by investigating the 
experimental and theoretical performance of innovative geometries. Characterization of dehumidifier geometries is an important step toward achieving a high-performance dehumidifier for solar desiccant cooling systems.

This report documents the efforts of design, fabrication, and instrumentation of the SERI Single-Blow Test Facility and also the design and fabrication of a highly uniform silica-gel parallel-plate test dehumidifier. Transient experiments were performed, and the results were compared with available heat and mass transfer models. This research was performed at the Solar Energy Research Institute (SERI) in FY 1984 and the early part of FY 1985 under task 3009.10 of the Thermal Sciences Research Branch for the Solar Desiccant Cooling Program.

The author would like to acknowledge the contribution of James Dolan, master technician, for assisting in the design and fabrication of the test facility and the test dehumidifier, Sung-Ho Jo, laboratory technician, for instrumentation of the facility, and Terry Penney for his guidance during the course of this work. Review comments by Kenneth Schultz and Eric Van den Bulck, University of Wisconsin; Ian Maclaine-cross, University of New South Wales, Australia; and Frank Kreith, SERI, are appreciated.

A. A. Pesaran

Ahmad A. Pesaran

Approved for

SOLAR ENERGY RESEARCH INSTITUTE

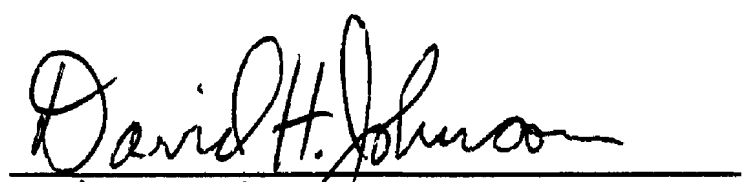

David H. Johnson, Manager

Thermal Sciences Research Branch

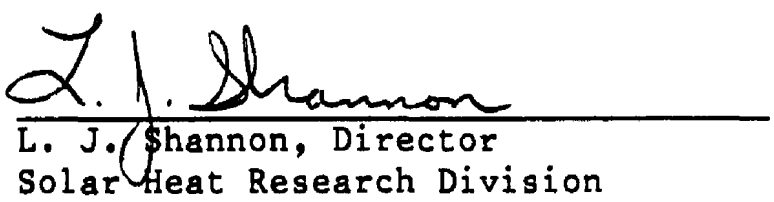




\section{SUMMARY}

\section{Objectives}

The objective of this work is to design, fabricate, and test a single-blow test facility to obtain transient experimental data on solid desiccant dehumidifiers with different geometry/material combinations.

\section{Discussion}

The SERI single-blow test facility was designed, fabricated, and tested (mass airflow rate $=50-120 \mathrm{scfm}$, temperature $=25^{\circ}-90^{\circ} \mathrm{C}$, and humidity ratio $=$ $0.005-0.03 \mathrm{~kg} / \mathrm{kg}$ ). A silica-gel parallel-plate dehumidifier with highly uniform passages was designed and fabricated as the first test article. The facility operates under typical conditions that are encountered in operation of solar desiccant cooling systems (e.g., temperatures of $35^{\circ}-90^{\circ} \mathrm{C}$ and humidity ratios of $0.012-0.025 \mathrm{~kg} / \mathrm{kg}$ ). A 1 imited number of single-blow experiments were performed, and transient heat and mass transfer data, as well as pressure drop data across the dehumidifier, were obtained. A single-blow test was performed by passing a process airstream through a desiccant dehumidifier to characterize the dehumidifier's transient heat and mass transfer performance. This is part of the Solar Energy Research Institute's (SERI) efforts to characterize the performance of promising solar-energyregenerated dehumidifiers and validate heat and mass transfer models for design purposes. Available heat and mass transfer models originally used for packed beds were extended to the parallel-plate geometry, and the experimental data were compared with model predictions. Pressure drop measurements were also compared with model predictions of the fully developed laminar flow theory.

\section{Conclusions and Recommendations}

The comparisons between the predictions of the "lumped-capacitance" model and the experimental data were generally satisfactory, within $10 \%$ for adsorption and $30 \%$ for desorption cases. The agreements were better for adsorption cases than desorption ones as reported by other investigators. The measured pressure drops across the parallel-plate dehumidifier were within $15 \%$ of the predicted pressure drops, which is reasonable.

This lumped-capacitance model can be used by researchers and industry to reasonably predict the transient performance of a desiccant dehumidifier, which can provide design information. The single-blow test facility can provide data on dehumidifiers with different geometry/material combinations. These data can be used to validate and improve the models that predict dehumidifier performance, which can later be used in designing dehumidifiers. Industry can also use these data to compare different dehumidifiers and select one to suit a particular need.

A "solid-side resistance" model that does not assume symmetrical diffusion in the particles and that is more sophisticated than the "lumped-capacitance" model was recommended for more accurately predicting dehumidifier 
performance. More comprehensive experimental data on the silica-gel parallelplate dehumidifier and other promising geometries (e.g., staggered parallel strip) and desiccants need to be obtained, which will result in the evaluation of their potential as advanced geometry/material combinations for desiccant dehumidifiers. The method of moments is recommended to estimate the heat and mass transfer coefficients from the transient heat and mass transfer data. 
Nomenclature......................................... ix

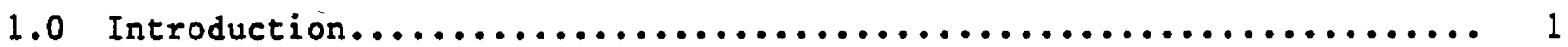

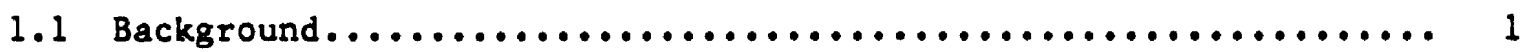

1.2 Purpose of this Work............................... 4

2.0 Description of the single-Blow Test Facility................ 5

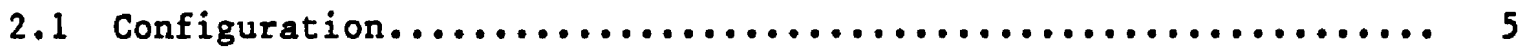

2.2 Instrumentation and Control............................ 9

3.0 Description of Parallel-Plate Test Article.................. 14

4.0 Experimental Procedure............................... 19

4.1 Preparation of the Test Article....................... 19

4.2 Process (Adsorption/Desorption)........................ 19

5.0 Heat and Mass Transfer Models........................... 21

5.1 Governing Equations............................. 21

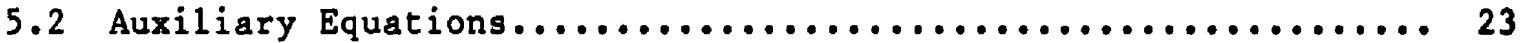

5.3 Pressure Drop Analysis............................. 25

6.0 Results and Discussion............................... 27

7.0 Conclusions and Future Work........................... 33

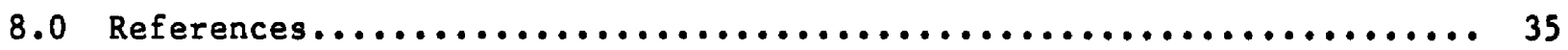

Appendix A Listing of Programs............................ 38

Selected Distribution List............................... 50 


\section{LIST OF FIGURES}

$\underline{\text { Page }}$

1-1 The Ventilation Cycle Desiccant Cooling System................ 2

2-1a System Adsorption Stream Capabilities...................... 6

2-1b System Regeneration Stream Capabilities.................... 7

2-2 Single-Blow Test Facility.............................. 8

2-3 Test Section and Measuring Instruments of the Single-Blow

Test Facility...................................... 10

2-4 Measurement Locations of the Test Facility.................. 10

2-5 A Thermocouple Junction............................... 11

2-6 Air Sampler, Thermocouple Array, and Test Article in the Test Section......................................... 12

3-1 A Silica-Gel-Coated Polyester Tape with Attached Spacers.......... 15

3-2 Parallel-P1ate Test Article............................ 15

3-3 Supporting Frame of the Parallel-Plate Test Article............. 16

3-4 Finished Paralle1-Plate Dehumidifier Test Article.............. 16

3-5 Cross-Sectional View of the Parallel-Plate Test Article........... 17

6-1 Comparison of Experimental and Predicted Results for Exp. 1....... 28

6-2 Comparison of Experimental and Predicted Results for Exp. 3....... 28

6-3 Comparison of Experimental and Predicted Results for Exp. 4....... 29

6-4 Comparison of Experimental and Predicted Results for Exp. 5....... 29

6-5 Friction Factor versus Reynolds Number--Measured and Predicted..... 31

6-6 Measured vs. Predicted Pressure Drop..................... 32 


\section{LIST OF TABLES}

$\underline{\text { Page }}$

3-1 Specification of the Parallel-Plate Test Article Dehumidifier....... 18

6-1 Experimental Parameters............................... 27

$6-2$ Pressure Drop Results............................... 32 


\section{NOMENCLATURE}

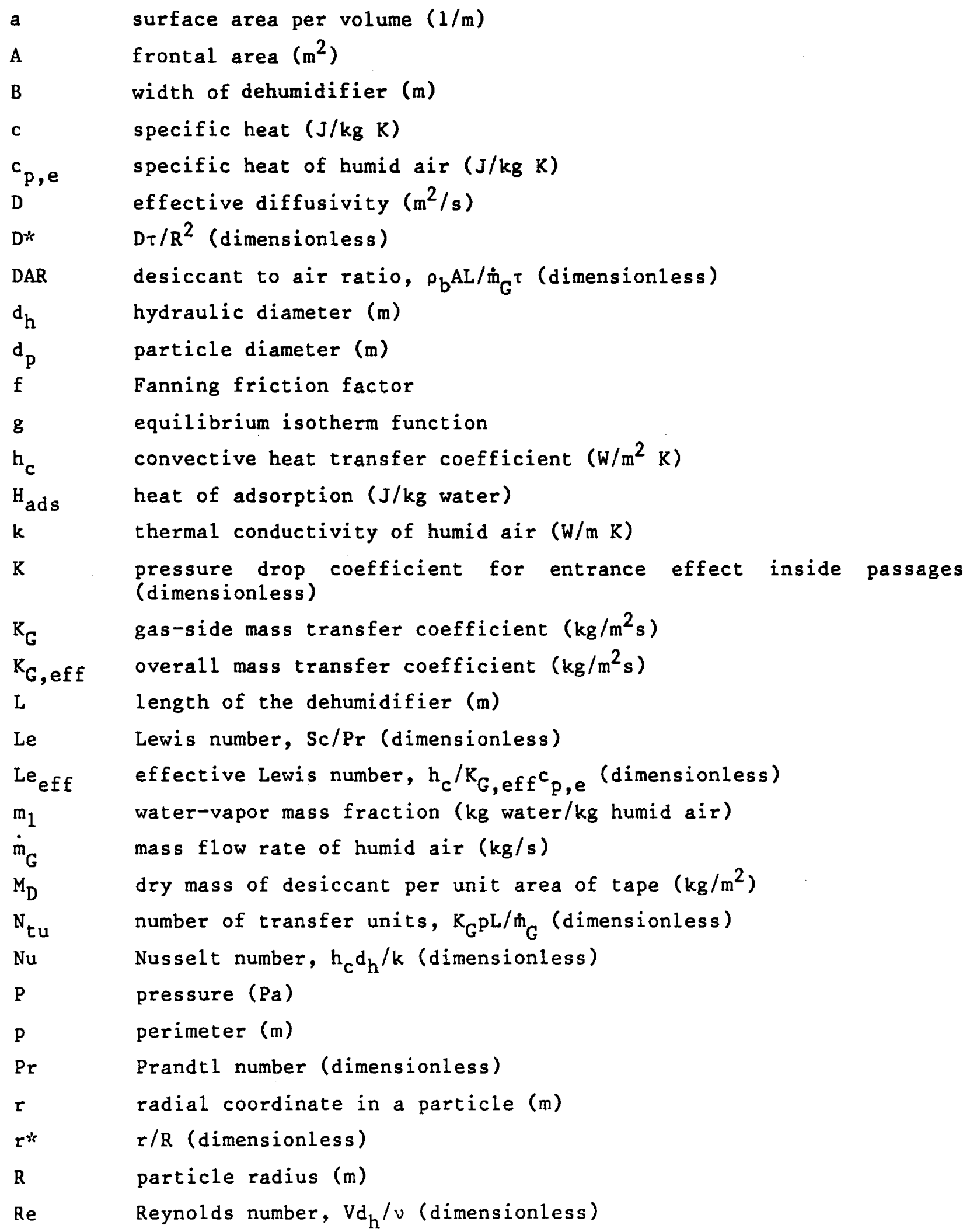




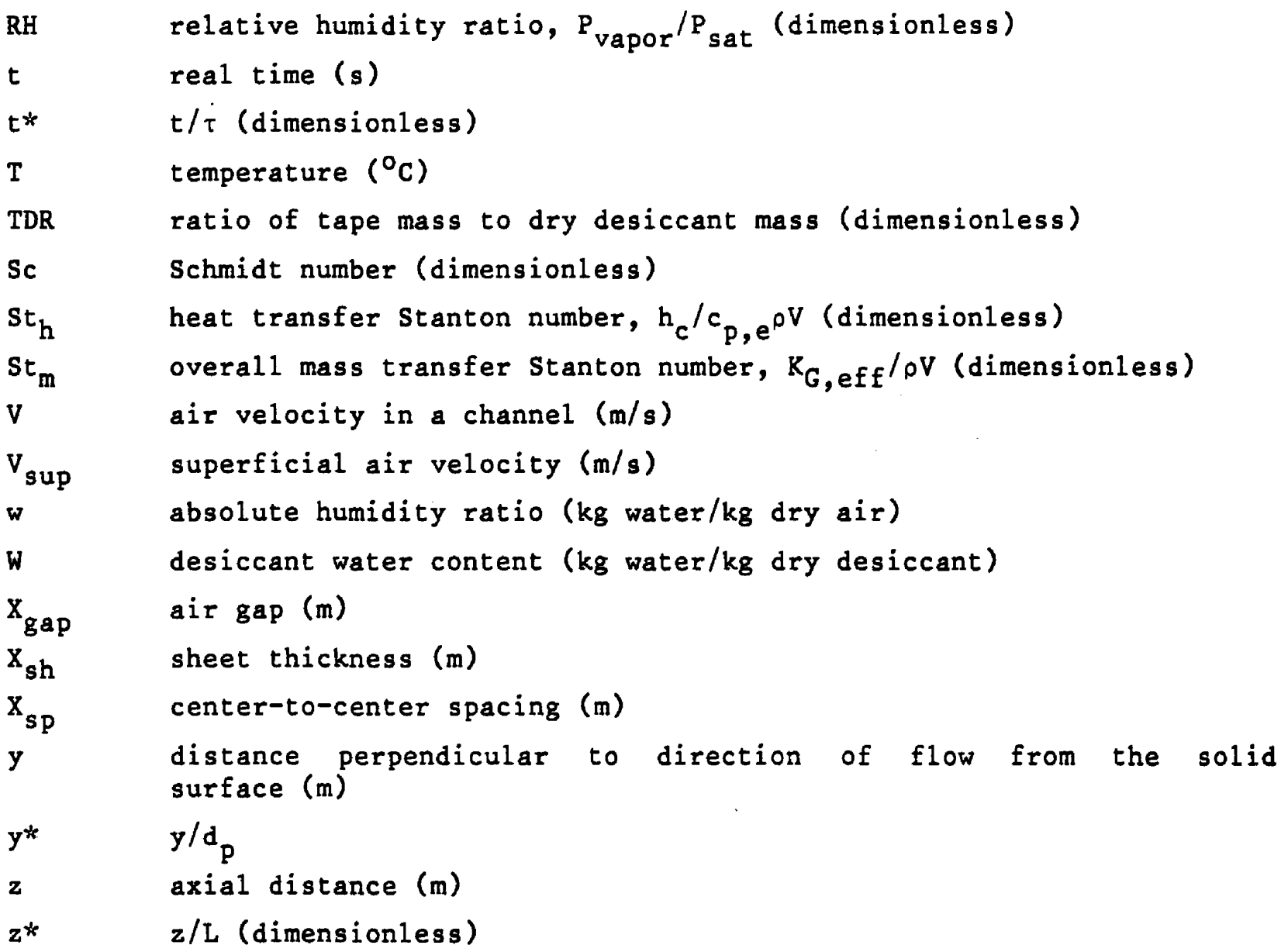

\section{Greek symbols}

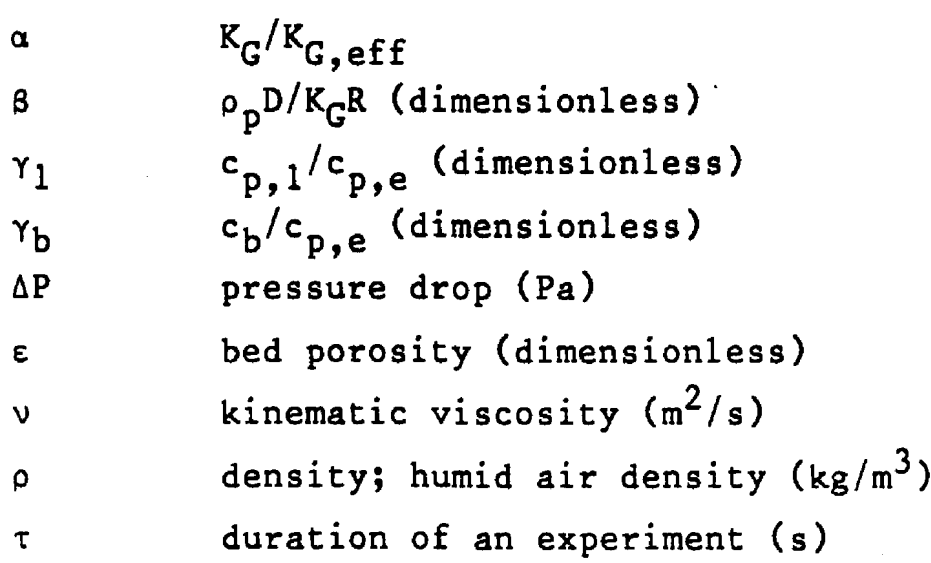




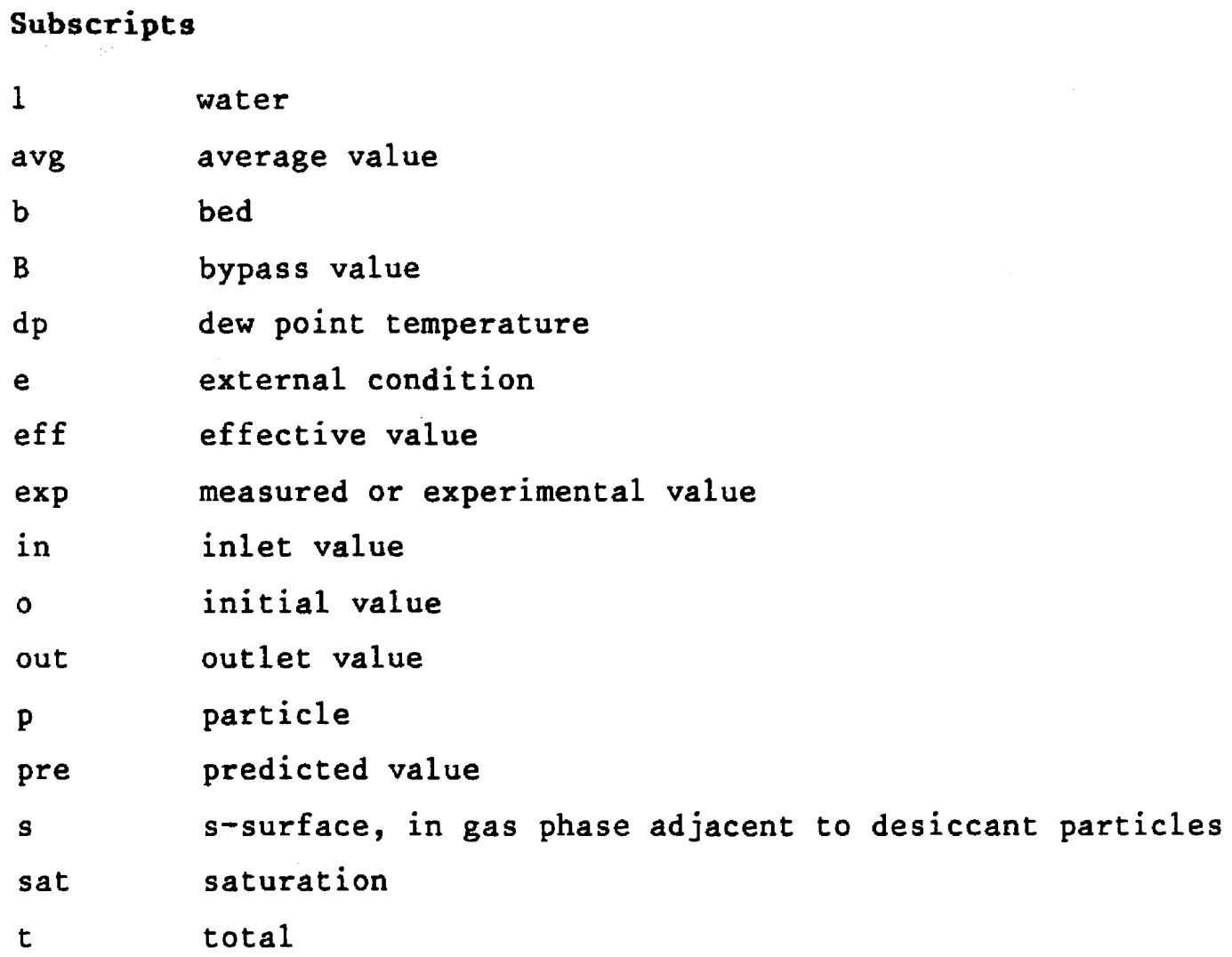




\subsection{INTRODUCTION}

\subsection{Background}

Open-cycle solid desiccant cooling is one of the promising methods of solar cooling. Solar desiccant cooling coupled with evaporative cooling has received considerable attention in the last several years as a mechanically simple solar-fired option to conventional vapor compression air-conditioning systems. The desiccant cooling system involves passing process air (which is warm and humid) through a desiccant bed for drying, and subsequent evaporative cooling to provide conditioned air. The desiccant is regenerated with hot air provided by solar collectors. A typical desiccant cooling system (as seen in Figure 1-1) consists of two evaporative coolers, a regenerative heat exchanger, a solar heater, and a desiccant dehumidifier [1]. Several studies have indicated that desiccant cooling systems can be competitive with vapor compression air-conditioning if thermal coefficients of performance (COPs) greater than 1.2 can be obtained [2,3,4]. The thermal performance of the system depends on the efficiencies of each component. Efficient and low-cost components should be used so that these systems can be economically viable. The state of technology in solid desiccant dehumidifiers for air conditioning applications is relatively new compared with other components. Development of desiccant dehumidifiers with high-performance, low-pressure drop, and low cost is a crucial step in making the desiccant cooling systems competitive with vapor compression systems. The efficiency of a desiccant dehumidifier, for the most part, depends on the type of desiccant used and the geometry of the dehumidifier.

The most common solid desiccant material proposed for solar desiccant cooling application is silica gel $[4,5,6]$ due to its high moisture recycling capacity compared with other industrial desiccants. Jurinak [4] characterized the material properties that influence the performance of dehumidifiers. These interrelating properties are maximum water capacity, isothermal shape, heat of adsorption, hysteresis upon thermal cycling, moisture diffusivity, and thermal capacitance. Jurinak concluded that among those commercially available, microporous silica gel is an attractive material for dehumidifier construction and can result in relatively good dehumidifier performance. However, to improve the thermal performance and reliability while reducing the cost of dehumidifiers, desiccant materials with improved properties over silica gel are needed. Polymers with the required desiccant properties can be used to fabricate cost-effective dehumidifiers. SERI has begun to characterize and evaluate polymers for their potential as advanced desiccants. The Gas Research Institute is involved in identifying and eventually developing desiccants that can improve the performance of gas-fired desiccant cooling systems.

The configurations that researchers have used for desiccant dehumidifier research are packed bed $[1,5,6]$, Illinois Institute of Technology (IIT) Teflon fiber plates [7], Institute of Gas Technology (IGT) corrugated structure [8], and coated parallel plate $[9,10,11]$. Traditionally, long, packed beds have been used in commercial and industrial applications where parasitic power losses are not a major concern. However, in air-conditioning applications 

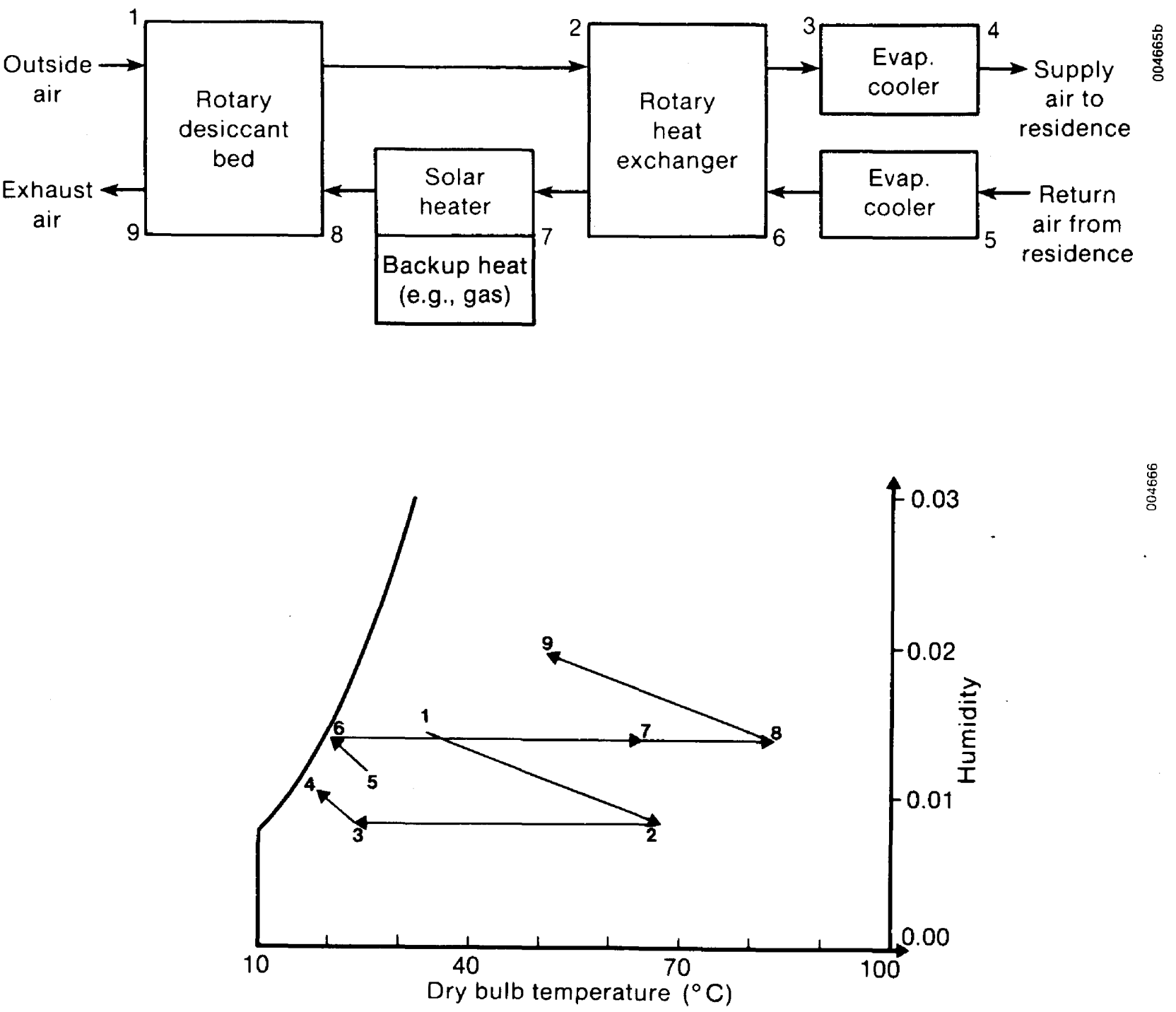

Figure 1-1. The Ventilation Cycle Desiccant Cooling System

there is a need to have low parasitic power losses. This resulted in the use of thin packed beds with large cross-sectional areas $[6,12]$, which make the dehumidifier large and undesirable.

The dynamic performance of packed beds was investigated theoretically and experimentally $[1,5,6,13,14]$. The ratio of heat transfer stanton number to friction factor $\left(\mathrm{St}_{h} / \mathrm{f}\right.$ ) for packed beds is about 0.06 ( $\operatorname{Re}=50$ ), while the ratio of overall mass transfer stanton number to friction factor ( $\mathrm{s}_{\mathrm{m}} / \mathrm{f}$ ) of packed beds is even lower (about 0.02 ) due to large diffusional solid-side resistance of moisture transfer in the particles [15]. The ratios of Stanton 
numbers to friction factor $\left(S t_{h} / f\right.$ and $\left.S t_{m} / f\right)$, or the ratios of heat or mass transfer coeffieient to pressure drop, are measures of compactness and performance of the dehumidifiers. For a given pumping power the geometries with higher $S t_{h} / f$ and $S t_{m} / f$ provide high transfer rates and thus are more efficient. Therefore, smaller dehumidifiers can be used in a cooling system. Large values of $\mathrm{St}_{\mathrm{h}} / \mathrm{f}$ and $\mathrm{St}_{\mathrm{m}} / \mathrm{f}$ are desired for dehumidifier geometries. IGT [8] made an effort to improve $\mathrm{St}_{\mathrm{h}} / \mathrm{f}$ by using a corrugated structure on which particles of a molecular sieve were impregnated. The $\mathrm{St}_{\mathrm{h}} / \mathrm{f}$ of fully developed laminar flow with constant heat flux at walls for a corrugated structure is about 0.32 . No data on $\mathrm{St} / \mathrm{f}$ has been reported, but it can be estimated to be $30 \%$ to $60 \%$ lower than $\mathrm{St}_{\mathrm{h}}$ 拜.

Researchers at IIT [7], the University of California at Los Angeles (UCLA) $[9,16,17]$, and the Solar Energy Research Institute (SERI) [10] made efforts to increase the $S t_{h} / f$ and the $\mathrm{St}_{\mathrm{m}} / \mathrm{f}$. The dehumidifier designed in IIT basically consists of silica gel sheets that form laminar flow channels. The silica gel sheets were made by bonding silica gel particles (average diameter $9 \mu \mathrm{m}$ ) with a fine Teflon web [7]. The $S t_{h} / f$ of the IIT concept is 0.49 under fully developed laminar flow conditions while its $\mathrm{St}_{\mathrm{m}} / \mathrm{f}$ is about $0.16[7,15]$ due to diffusional resistance of moisture transfer in the Teflon web.

The UCLA dehumidifier concept [9] consists of parallel plates coated with a layer of fine silica gel particles $(120-250 \mu \mathrm{m})$. Researchers at SERI [10] combined the UCLA concept with one using a rotary heat exchanger construction developed by CSIRO in Australia [18]. The SERI dehumidifier has parallel channels of double-sided polyester tapes with an adhesive on which fine particles of silica gel are bonded. The $S t / f$ of laminar flow channels is 0.49 , which is higher than the other dehumidifier geometries except for the IIT concept. It is estimated that the $S t / f$ of the UCLA and SERI concept is about 0.41 [10], which is higher than the fIT concept. Since larger $\mathrm{st} / \mathrm{f}$ and $\mathrm{St}_{\mathrm{m}} / \mathrm{f}$ would result in more compact and efficient dehumidifiers, the coated parallel-plate concept appears to have a great potential to provide an advanced, cost-effective dehumidifier.

Researchers at UCLA $[16,17]$ performed adiabatic single-blow experiments on a bench-scale parallel-plate test article. Fine grains of silica gel (average diameter 120 to $250 \mathrm{\mu m}$ ) were bonded to one side of $0.76-\mathrm{mm}$-thick Lexan plastic sheets using a thin layer of silicon rubber adhesive to produce a sandpaper-like surface. The coated sheets were stacked and spacers were used to form parallel-walled, laminar flow channels. The experimental results using this test dehumidifier were compared with a lumped-capacitance heat and mass transfer model. The agreement was generally fair and the discrepancies were attributed to heat losses and shortcomings of the model.

SERI tested a smal1-scale prototype parallel-plate dehumidifier [10]. The prototype was built by coating both sides of a double-sided polyester tape with fine silica gel particles and then spirally winding the coated tape to form parallel-walled, laminar flow passages. Single-blow adsorption and desorption experiments were performed under adiabatic conditions, and the results were compared with a pseudo steady-state model. The equations for simple steady-state counterflow heat and mass exchangers were used in the model for predicting the dehumidifiers' performance. Predictions were in 
reasonable agreement with the experimental results for adsorption cases and were relatively poor for desorption cases. The diffusional resistance in the silica gel particles was estimated to be $20 \%-30 \%$ of gas-side film resistance and thus an overall transfer coefficient was used. This may be one of the reasons for the discrepancies observed between the model predictions and experimental results.

Heat and mass transfer models that properly account for moisture diffusion into the desiccant particles of parallel-plate dehumidifiers are required. These models should be compared with experimental data to further improve the models. These models can later be used in system analysis and component design.

\subsection{Purpose of this Work}

The objective of this work was to obtain transient experimental data on benchscale solid desiccant dehumidifiers under conditions typical of those encountered in solar desiccant cooling applications by fabricating a singleblow test facility and desiccant dehumidifier test articles. Another objective of the project was to extend and improve the available heat and mass transfer models to silica-gel parallel-plate dehumidifiers by comparing the experimental results and model predictions. The single-blow test facility can be used to obtain the performance of different dehumidifier geometries with different desiccant materials and provide data bases for comparing and selecting geometries/material combinations. This report describes a singleblow test facility and a silica-gel parallel-plate test article with limited test results and compares their test results with model predictions. Further experimental and theoretical efforts were scheduled in FY 1985 (task 3022.210). 


\subsection{DESCRIPTION OF THE SINGLE-BLOW TEST FACILITY}

\subsection{Configuration}

The single-blow test apparatus was conceived to obtain transient adsorption/ desorption experiments of a bench-scale dehumidifier. The reasonable area for the dehumidifier test section was chosen to be about $0.025 \mathrm{~m}^{2}$ to have a reasonably smal1-scale apparatus, but with small end effects on the dehumidifier. The geometry of the test section was chosen to be square (about $0.16 \mathrm{~m}$ $\times 0.16 \mathrm{~m}$ ) for ease of fabricating test dehumidifiers. The design of the test air velocity in a residential dehumidifier wheel was estimated to be about $1.2 \mathrm{~m} / \mathrm{s}$. Using this design velocity, the design air flow rate in the dehumidifier test section was then $0.03 \mathrm{~m} / \mathrm{s}$ (about $0.03 \mathrm{~kg} / \mathrm{s}$ or $63 \mathrm{scfm}$ ). A beltdriven centrifugal blower from a previous desiccant test loop [19] was available that could produce this flow rate. The maximum flow rate that this fan could produce was $0.045 \mathrm{~m} / \mathrm{s}$ (about $0.045 \mathrm{~kg} / \mathrm{s}$ or $100 \mathrm{scfm}$ ). The other design parameters at the design flow rate were
Range of inlet adsorption temperature
Ambient* to $40^{\circ} \mathrm{C}$
Range of inlet desorption temperature
$60^{\circ}$ to $90^{\circ} \mathrm{C}$
Range of inlet humidity ratio
Ambient* to $0.03 \mathrm{~kg} / \mathrm{kg}$

*temperature $20^{\circ}-25^{\circ} \mathrm{C}$; humidity 0.005 to $0.012 \mathrm{~kg} / \mathrm{kg}$

These air conditions cover the range of temperature and humidity that would be encountered in both recirculation and ventilation modes of operation for solar desiccant cooling systems, as shown in Figure 2-1.

To minimize duct requirements, the test rig was designed to use ambient air in the laboratory space. We found that in the winter, room air ordinarily is low in both dry-bulb temperature and moisture content and this permitted dehumidifier testing over the range of desired conditions. However, in the summer, the humidity level is high due to the evaporative cooling component of the building HVAC system, and we may not be able to operate at the desired conditions. In such a case, sufficient ducting supplies outside air, which is sufficiently low in humidity because of the dry Colorado climate. The exhaust air after adsorption/desorption tests is discharged to the laboratory space at this time.

The schematic of the single-blow test apparatus is shown in Figure 2-2. The setup consists of a duct heater, a humidifier, a multispeed blower, an orifice plate, the test section, and required instrumentation for measuring temperatures, pressure drops, humidities, and air flow rate. The heater and humidifier are mounted on a square duct cross-section of galvanized iron $[0.2 \times 0.2 \mathrm{~m}(8 \times 8 \mathrm{in.}), 20$ gauge $(0.85 \mathrm{~mm})$ thick]. A $0.15-\mathrm{m}$ (6-in.) diameter 20-gauge circular duct was chosen (because it is rigid and leakproof) for connecting the blower to the orifice plate and then to the test section and finally to the exhaust. A smooth transition section from circular 


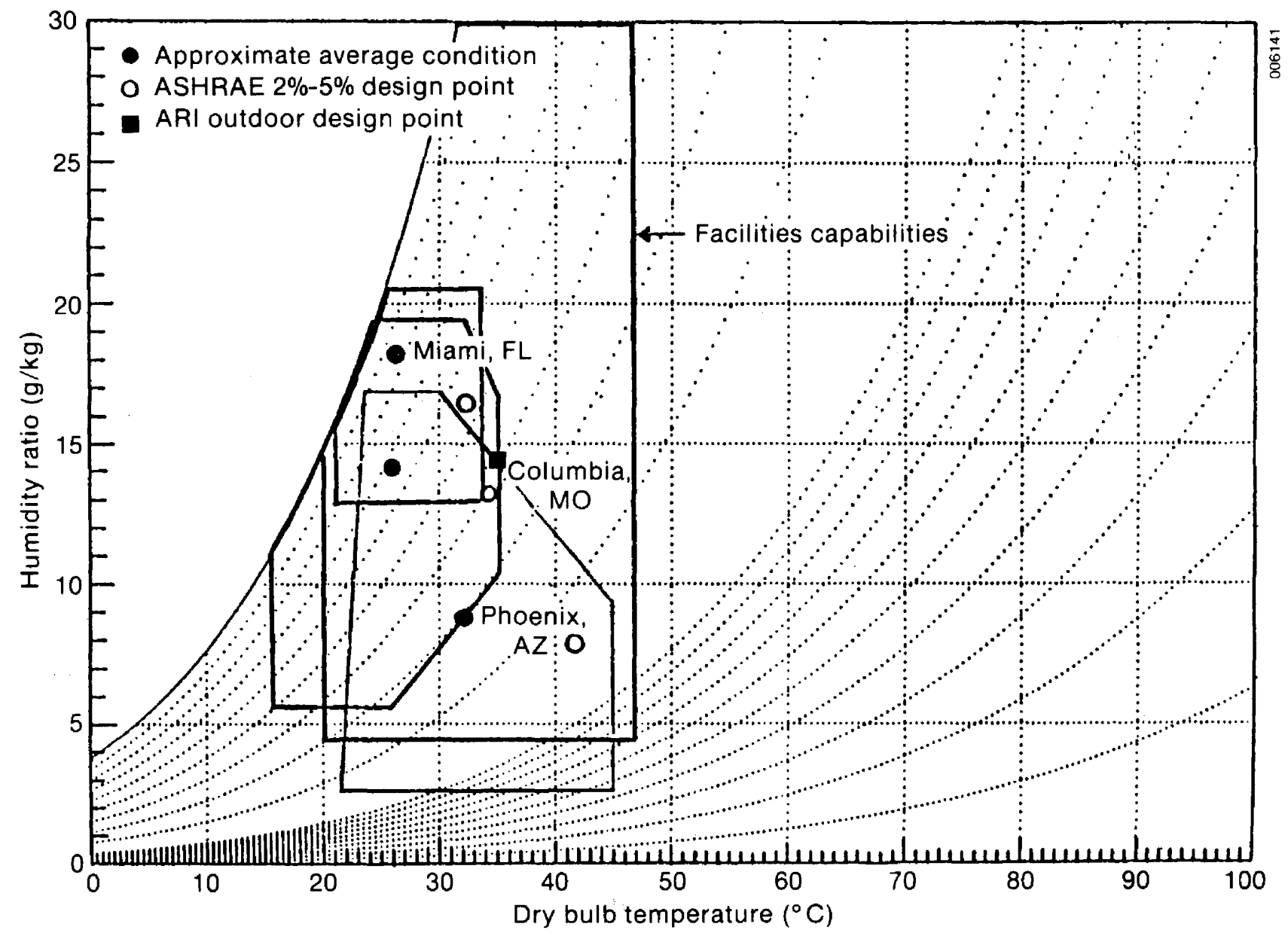

Figure 2-1a. Facility Adsorption Stream Capabilities

to square was used to connect the circular duct to the square test section. The test section, which contains the test article, temperature sensors, air samplers, and pressure tap, has a cross-section of $0.161 \mathrm{~m} \times 173 \mathrm{~m}$ and is $0.6 \mathrm{~m}$ long. The test section can be opened from two sides for any modification required. Two walls of the test section, which can be removed, are made of Lexan for flow visualization. Major components are connected using bolted flanges and are supported on stands approximately $0.6 \mathrm{~m}$ above the floor. The bolted flanges give the system the capability of easy access to the components in case problems arise or modifications are necessary.

The finned tubular duct heater is $4.1 \mathrm{~kW}$ (manufactured by Wellman) and needs 208 volts and a 3-phase power supply and heats up the process air for both adsorption (up to $40^{\circ} \mathrm{C}$ ) and regeneration (up to $90^{\circ} \mathrm{C}$ ). Humidification of process air is accomplished by injecting steam produced by an electric boiler through a duct humidifier. The 50-kW, 480-volt boiler (manufactured by Electro-Steam) used for this setup is shared with the SERI Cyclic Test Facility. The dry steam is injected into the system using a duct humidifier (model ST-50 manufactured by Walton) at a rate of 0.2 to $3 \mathrm{~kg} / \mathrm{h}$. The capacity 


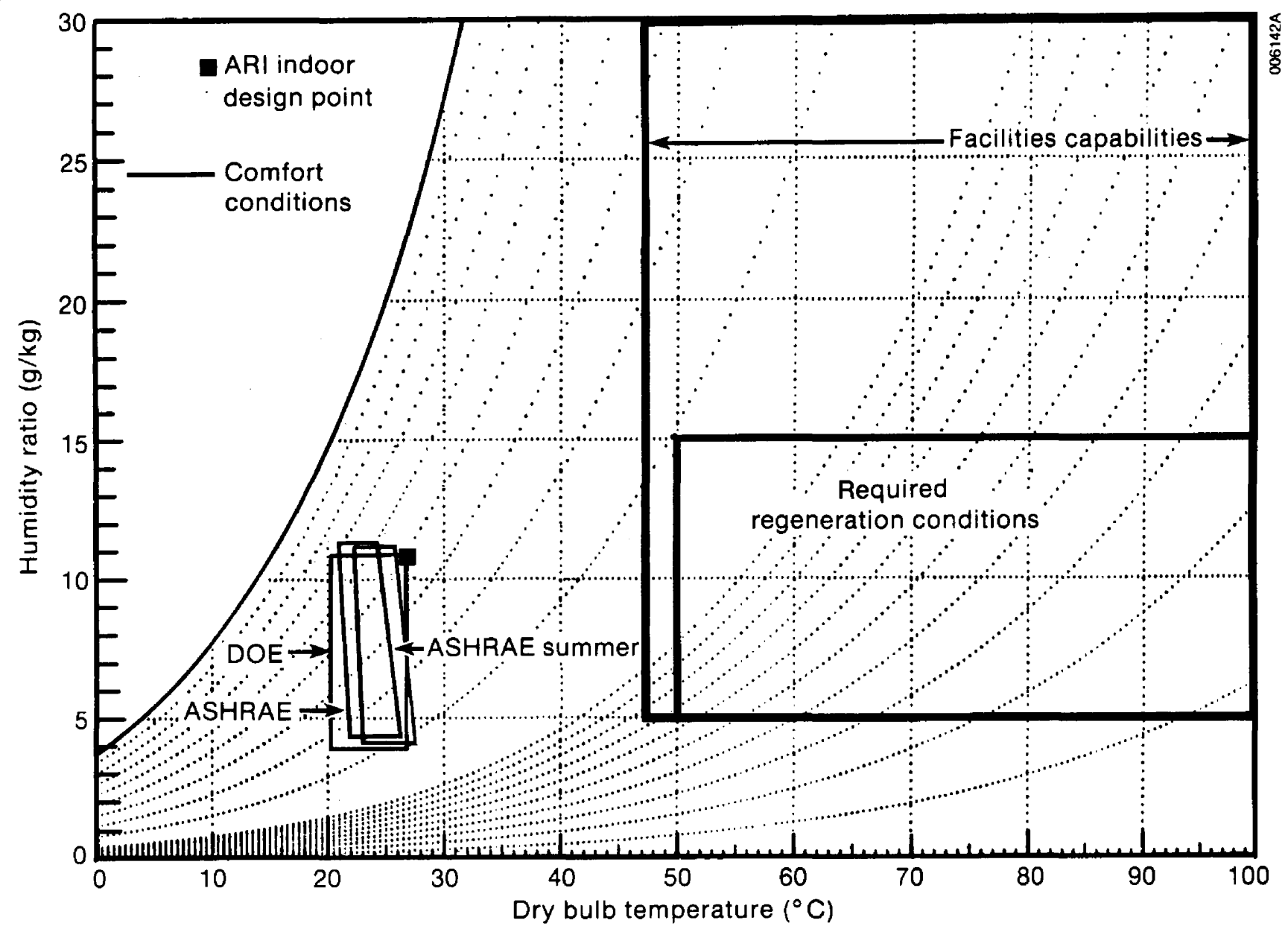

Figure 2-1b. Facility Regeneration Stream Capabilities

and the arrangement of the boiler is such that the operation of one test facility does not interfere with the operation of the other one.

The belt-driven air blower (manufactured by NYB) has $0.3-m$ (12-in.) diameter straight radial blades and is driven by an externally mounted, 2-speed (1140 and $1725 \mathrm{rpm}$ ), 230-V single-phase 994-W electric motor (manufactured by General Electric). Using a stepped-cone pulley system and a duct damper, air flow rates of 0.0047 to $0.047 \mathrm{~m}^{3} / \mathrm{s}$ (10 to $100 \mathrm{scfm}$ ) can be provided. Two butterfly valves (manufactured by Keystone) and a gate valve (GV) are used to send air through the test section (BV1 and GV open, BV2 closed) or through the bypass (BV1 and GV closed, BV2 open). These valves are leak-proof when closed. The gate valve is expected to produce only small disturbances to flow after entering the test section.

The single-blow test facility is installed in the west high bay (1aboratory 158) of SERI's Field Test Laboratory Building (FTLB). Figure 2-3 is a photograph of the test section of the single-blow test facility. 


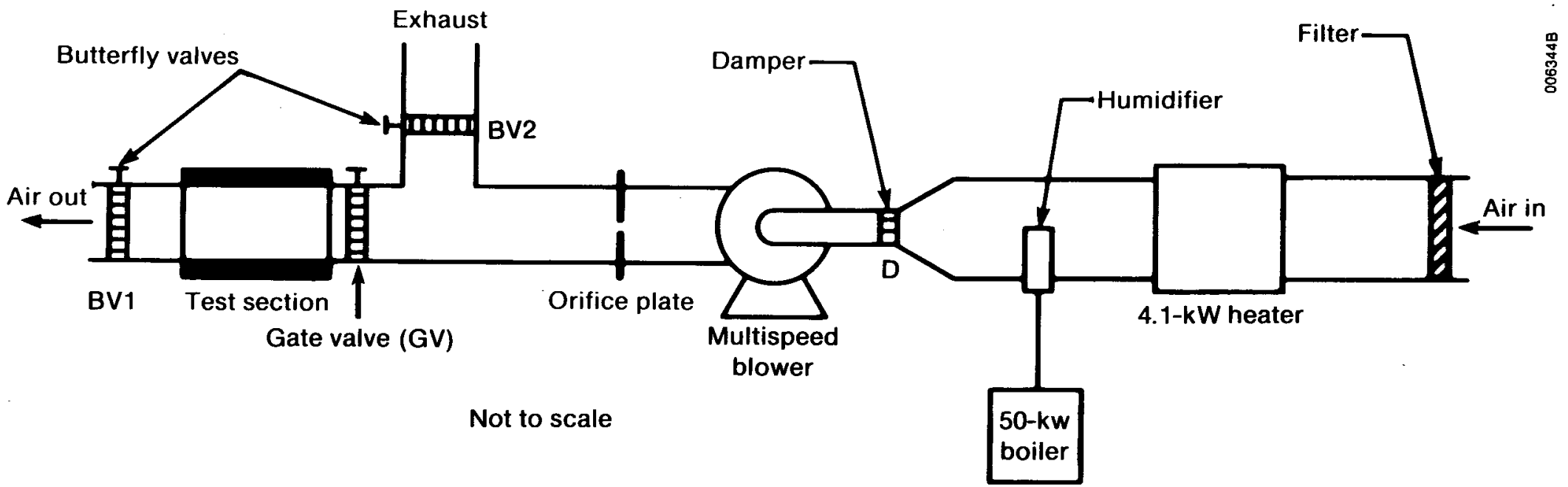

Figure 2-2. Single-Blow Test Facility 


\subsection{Instrumentation and Control}

Important quantities to measure in the single-blow experiments are inlet and outlet temperatures and humidities, flow rate, and pressure drop across the dehumidifier. The temperature and humidity of air going through the bypass are also measured before introducing air to the test article. Figure 2-4 schematically shows measurement locations in the test facility.

The data acquisition system consists of a HP-9845A desk-top computer with a HP-3497A scanner/multiplexer/digital voltmeter. Both of these units were available at SERI. The voltmeter was recently calibrated to the manufacturer's specifications. The accuracy of the voltmeter is less than $0.03 \%$ of the reading with a resolution of $1 \mu \mathrm{V}$.

Temperature measurements are made using gauge 30 (0.25-mm-diameter) copperconstantan (type T) thermocouples. Average inlet and outlet temperatures are obtained by an array of four thermocouples connected in series. The arrays are located in the duct to obtain an area weighted average. The electromotive force (emf) produced in this manner is four times the emf of a single thermocouple and thus the error in reading voltages by the voltmeter is reduced by a factor of four.

Each thermocouple junction is designed [10,18] with sufficient bare wire (see Figure 2-5) to reduce conduction and radiation errors. The actual temperature measuring point of the sensor is not at the junction but at the copper side. For this study it is about $5 \mathrm{~mm}$ on the copper side. The accuracy of the temperature measurement depends on the air velocity. The length of bare copper wire is about three times longer than bare constantan, since its conductivity is higher. The emmisivity of bare wires is very low when clean $(0.03)$. With thin wires and air flow perpendicular to the wire, high convective heat transfer rates are obtained. The conduction error is estimated to be less than $0.01^{\circ} \mathrm{C}$, with a radiation error of less than $0.2^{\circ} \mathrm{C}$ at an air velocity of $0.8 \mathrm{~m} / \mathrm{s}$. The thermocouples are connected to an isothermal box. The emf generated because of temperature difference between junctions and the isothermal box is measured by the voltmeter of the HP-3497A through a voltage card. An ice bath provides a reference emf so that absolute values of temperatures can be measured. The use of an ice bath, instead of a voltagecompensated ice junction, reduces the error of reference junction to $\pm 0.01^{\circ} \mathrm{C}$. The emf of the thermocouple junction at the measuring location relative to the ice box can be used to obtain the temperature of the junction. To convert this emf to temperature, a third-order regression fit, based on the voltage-temperature calibration data obtained at SERI, was used with an error of $\pm 0.04^{\circ} \mathrm{C}$ over the range of $0^{\circ}$ to $100^{\circ} \mathrm{C}$. Assuming the above errors combine randomly, the uncertainty in temperature measurement is expected to be less than $0.3^{\circ} \mathrm{C}$.

When the process air flows through the bypass, the temperature of the air is monitored by a single thermocouple junction $\left(T_{B}\right)$. This thermocouple is also used for controlling the heat input by the heater and thus controlling the dry bulb temperature. This thermocouple is connected to a temperature proportional controller (manufactured by Omega Engineering). The controller 


\section{S\#P *}

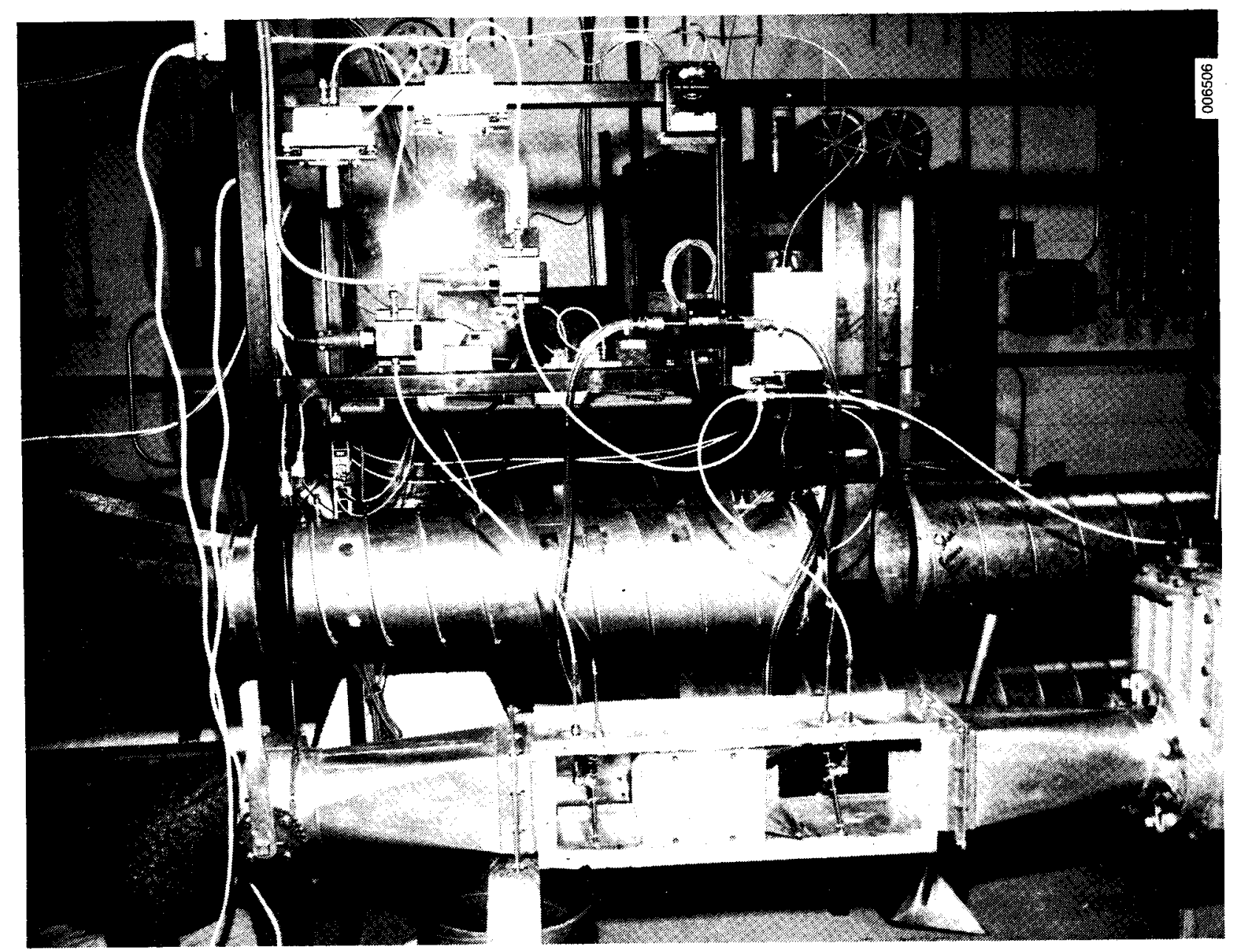

Figure 2-3. Test Section and Measuring Instruments of The Single-Blow Test Facility (insulation removed)

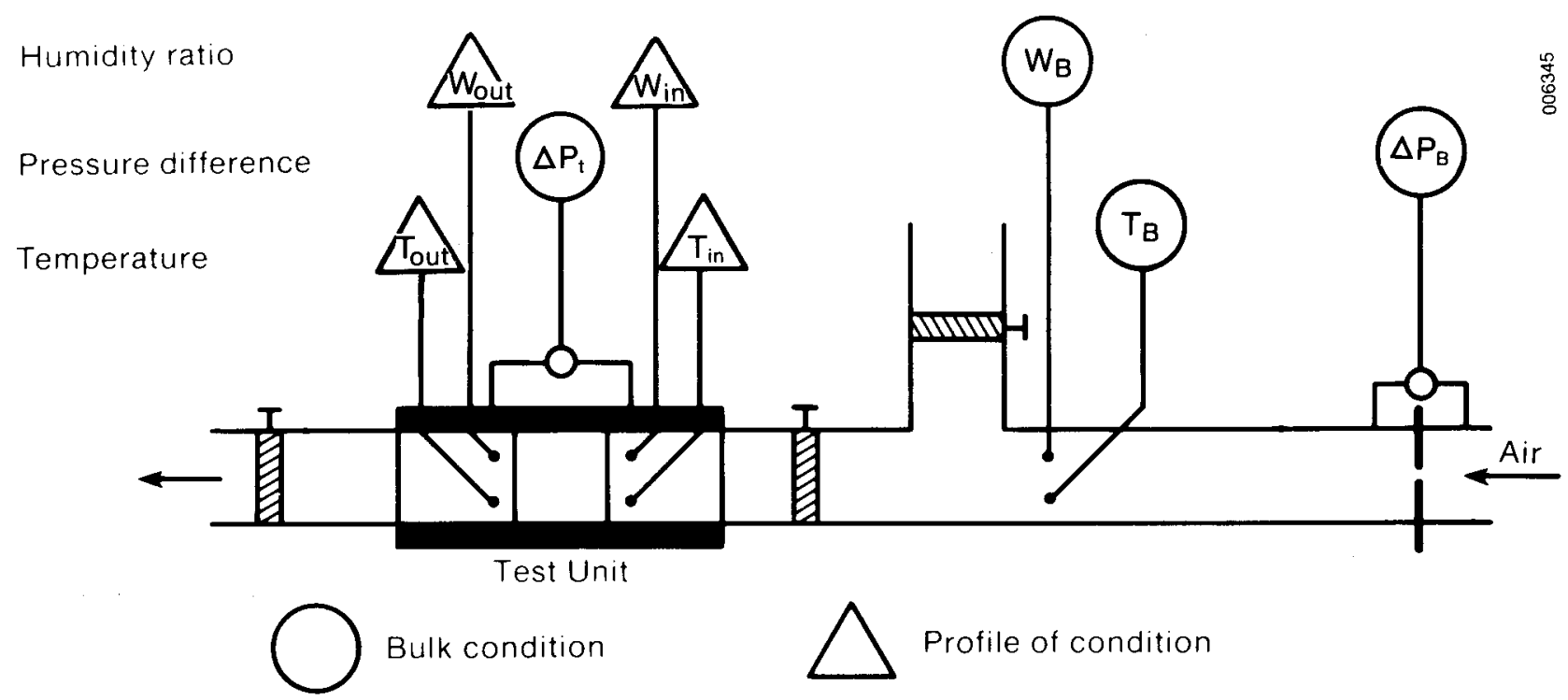

Figure 2-4. Measurement Locations of the Test Facility 


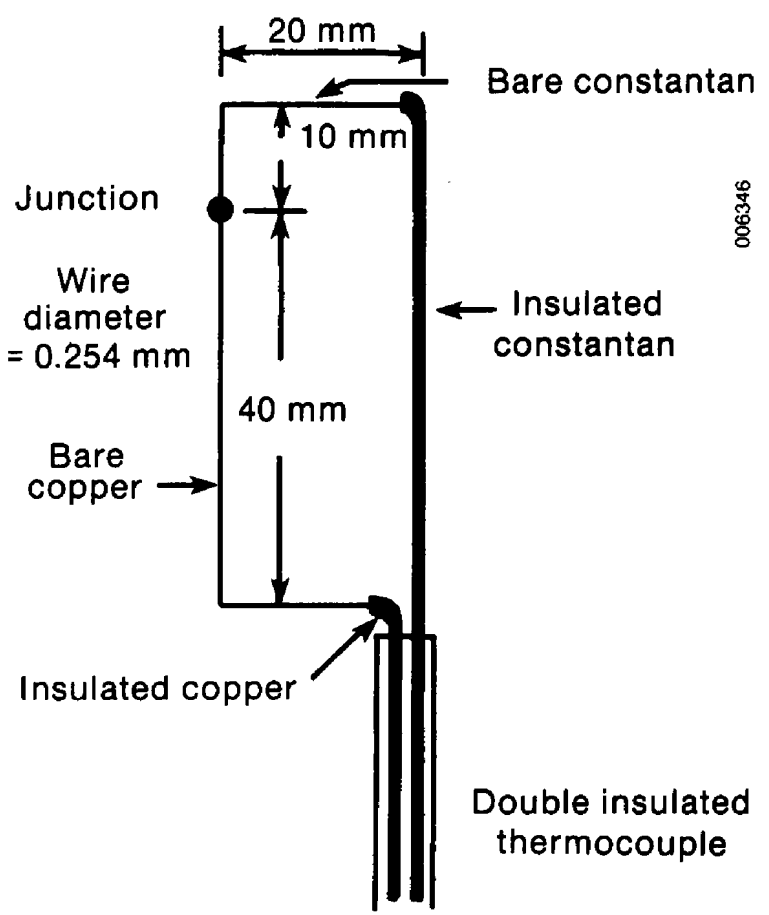

Figure 2-5. A Thermocouple Junction

measures the difference between the process air temperature and the setpoint temperature and sends a signal to the heater to be turned on or off. The amount of heat required is determined by the rate of on and off cycles. The set-point temperature can be approached within $\pm 0.3^{\circ} \mathrm{C}$ with an oscillation period of up to about three minutes. It was found that the temperature control is quite acceptable for the purpose of this work.

Humidity measurements are made using optical condensation dew-point hygrometers (manufactured by General Eastern, Model 1100DP/1111D). The uncertainty of the sensors in measuring dew point temperature is $\pm 0.4^{\circ} \mathrm{C}$. Two dew-point hygrometers were purchased for this test facility. The average bypass and inlet dew-point temperatures were measured by a single dew point sensor using a three-way switching valve. The average outlet dew point temperature was measured using the second hygrometer. To ensure a representative air sample from the duct, the air for each hygrometer was drawn by a small pump from 1/4-in. air samplers with eight holes $0.8 \mathrm{~mm}$ in diameter. For the bypass the air sampler had four holes. The air samplers were arranged across the duct perpendicular to air flow so that air was sampled from the core of the air flow. See Figure 2-6 for a close-up of the air sampler and the thermocouple array.

Conversion of dew point temperature to humidity ratio was accomplished by the relation

where

$$
w=0.622 \frac{P_{s a t}\left(T_{d p}\right)}{P_{t}-P_{s a t}\left(T_{d p}\right)}
$$

$$
\begin{aligned}
\mathrm{w} & =\text { humidity ratio } \\
\mathrm{T}_{\mathrm{dp}} & =\text { dew point temperature } \\
\mathrm{P}_{\mathrm{t}} & =\text { total absolute pressure } \\
\mathrm{P}_{\text {sat }} & =\text { saturation pressure. }
\end{aligned}
$$

A correlation for saturation pressure as a function of temperature suggested by Maclaine-cross [20] was used that has an uncertainty of less than $\pm 0.1 \%$. The total uncertainty in calculating humidity ratio is estimated to be less than $3 \%[11]$. 

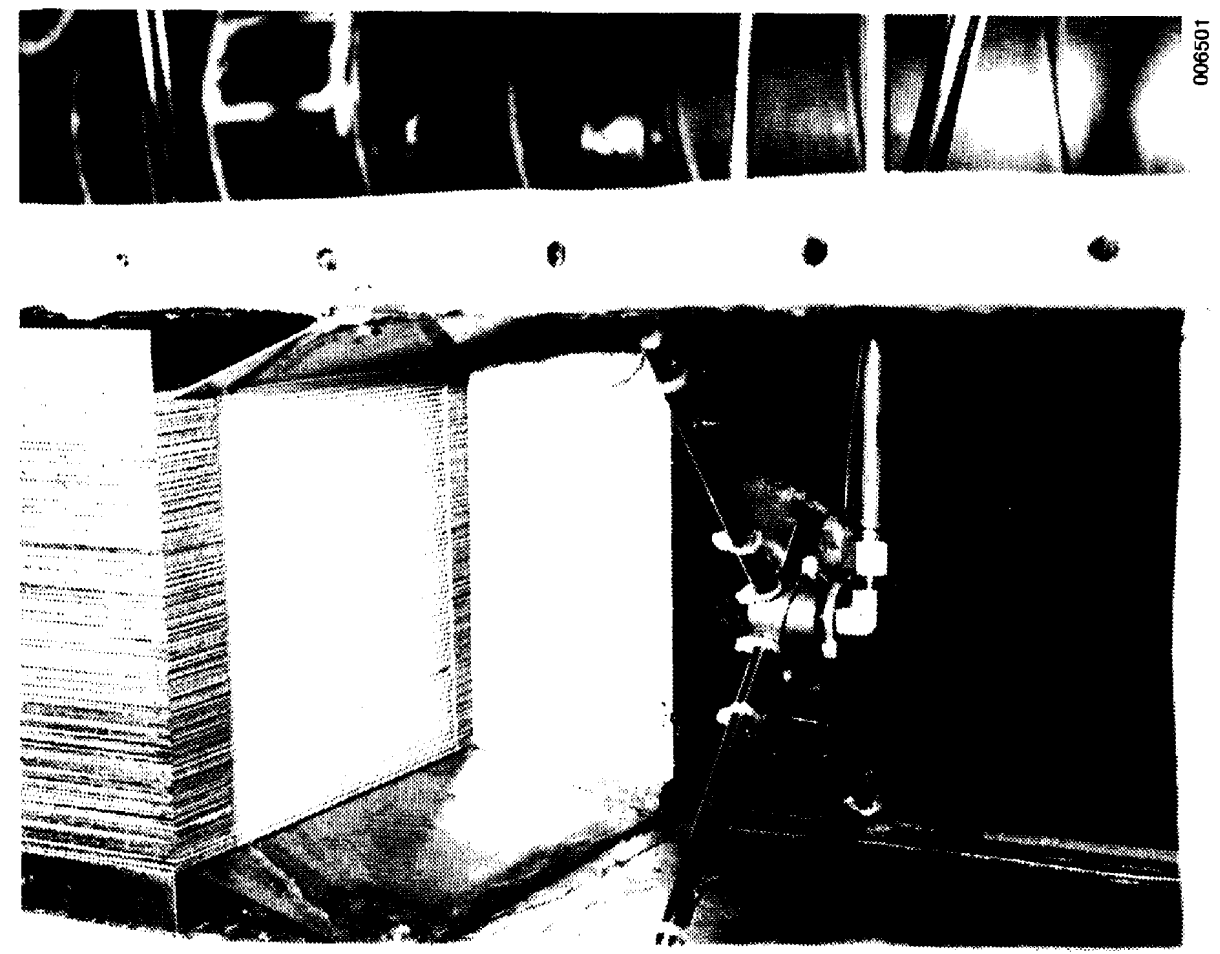

Figure 2-6. Air Sampler, Thermocouple Array, and Test Article in the Test Section. The thermocouple array is mounted on the air sampler.

The humidity of the process air was controlled by controlling the steam flow rate using an electronically operated value in the steam supply line. Electrical signals, based on comparing a set-point relative humiaity and the output of a resistance-type relative humidity sensor in the duct, controlled the opening of the valve. The fluctuation in dew point temperature of the process air in some of the tests was $\pm 2{ }^{\circ} \mathrm{C}$, which is unsatisfactory. The efforts in an FY 1985 project were successful in resolving this problem. The results from this project will be reported in a forthcoming report [21].

Flow rates were determined by measuring the pressure differences across ASME standard orifice plates. Three aluminum orifice plates with diameter ratios (orifice diameter/duct diameter) of $0.2,0.3$, and 0.4 were made to cover the range of flow rates $(0.004-0.047 \mathrm{~kg} / \mathrm{s})$. Ten diameters of straight duct upstream and six diameters of straight duct downstream of the orifice plate were installed to conform to ASME standards. A one diameter and a half diameter pressure tap (1D and 1/2D) were used for pressure drop measurements across the orifice plate. The maximum uncertainty in mass flow rate measurement is about $\pm 2 \%[11]$.

The pressure drop across the orifice plates and across the test dehumidifier were measured using capacitance-type pressure sensors (manufactured by MKS Instruments, Baratron type 221D) with a range of 0 to $10 \mathrm{~mm} \mathrm{Hg}$. The uncertainty in pressure drop measurements is expected to be less than $\pm 2.5 \%$ of the reading. The pressure transducers were calibrated with a Dwyer micrometer 


\section{SER *}

with an accuracy of $\pm 0.0005 \mathrm{~mm} \mathrm{Hg}$. The ambient absolute pressure was obtained using a capacitance-type sensor (MKS Instruments, Baratron type 220A) with an uncertainty of less than $1.7 \%$.

A data acquisition program called DAP, written in BASIC, monitored the experiments and also collected the data. Appendix A lists DAP. The output voltages from the measuring instruments are stored on a cartridge at an interval that can be changed during the experiments. These voltages can be analyzed with another program called PLOT that plots the experimental data in meaningful parameters, i.e., temperatures and humidities as a function of time. Appendix A also lists PLOT. 


\subsection{DESCRIPTION OF THE PARALLEL-PLATE TEST ARTICLE}

The test section in the Single-Blow Test Facility was designed to facilitate mounting various dehumidifier geometries with different desiccant materials. This design allows testing of promising geometry/material combinations. By measuring the performance of the geometry/material combinations one can identify their potential. In addition, small-scale test articles can be fabricated and tested in the single-Blow Test Facility for less money compared with testing a larger dehumidifier wheel in the Cyclic Test Facility.

The first test article we investigated in the single-Blow Test Facility for this study had a parallel-plate geometry. This test article simulates the silica-gel parallel-plate dehumidifier wheel that is under testing in the SERI Cyclic Test Facility. The single-blow test results provides supplemental information (such as nature and magnitude of solid-side resistance) for performance analysis of the rotary dehumidifier wheel. The single-blow results also provides data for comparison with, and validation of, detailed heat and mass transfer models. The silica-gel parallel-plate dehumidifier wheel tested in the SERI Cyclic Test Facility [22] had a manufacturing problem--the passages were not uniform due to sagging of the silica-gel-coated polyester film. In the design and fabrication of the bench-scale parallel-plate test article, we succeeded in preventing the problem of sagging and nonuniformity: The test article consists of a supporting frame, silica-gel-coated polyester tapes, and spacers.

The spacers of the test unit are made of $0.794-\mathrm{mm}(1 / 32-i n$.$) thick precision$ punched aluminum shims. The spacers are $25.4 \mathrm{~mm}$ ( 1 in.) wide and $0.20 \mathrm{~m}$ ( 8 in.) long with three holes of $12.7 \mathrm{~mm}(1 / 2 \mathrm{in.})$. The rods of the supporting frame go through these holes for keeping the spacers in place. Figure 3-1 is a photograph of the spacers along with a silica-gel-coated polyester tape. Figure 3-2 is a schematic of the parallel-plate test article. A double-sided polyester tape with acrylic adhesive is coated on both sides with fine particles of silica gel 177 to $297 \mu \mathrm{m}$ (mesh size 50 to 80) after they are attached to two spacers on each side. Figure 3-2 schematically shows this arrangement. The tape (film and adhesive) is 76- $\mathrm{m}$ (3-mil) thick, 0.167-m (6.57-in.) wide, and $0.203-\mathrm{m}$ ( 8 -in.) long. However, only $0.117 \mathrm{~m}$ ( $4.57 \mathrm{in.}$ ) of the width is covered with silica gel. The rest of the width is covered with the spacers from both ends; i.e., each tape is sandwiched between two spacers at each end.

The sheets (i.e., the silica-gel-coated polyester tapes with four spacers, Figure 3-1) are then stacked in the supporting frame. The supporting frame, as seen in Figure 3-3, is made of aluminum. The solid rods, which have a diameter of $12.7 \mathrm{~mm}$ ( $1 / 2 \mathrm{in.})$, were designed to have sufficient strength from bowing and bending caused by tension from the sheets. The supporting frame can be opened from both ends by unscrewing six screws and taking off the lids. The lids are $19 \mathrm{~mm}$ ( $3 / 4 \mathrm{in.})$ thick, $0.167 \mathrm{~m}(6.57 \mathrm{in.})$ wide, and $0.203 \mathrm{~m}$ ( $8 \mathrm{in.}$ ) long. The lids are cut in half and two sliding pins keep them together. Two back-off screws on one side of a half are provided to pull the two halves apart. This mechanism prevents the sheets from sagging. 


\section{SEP *}

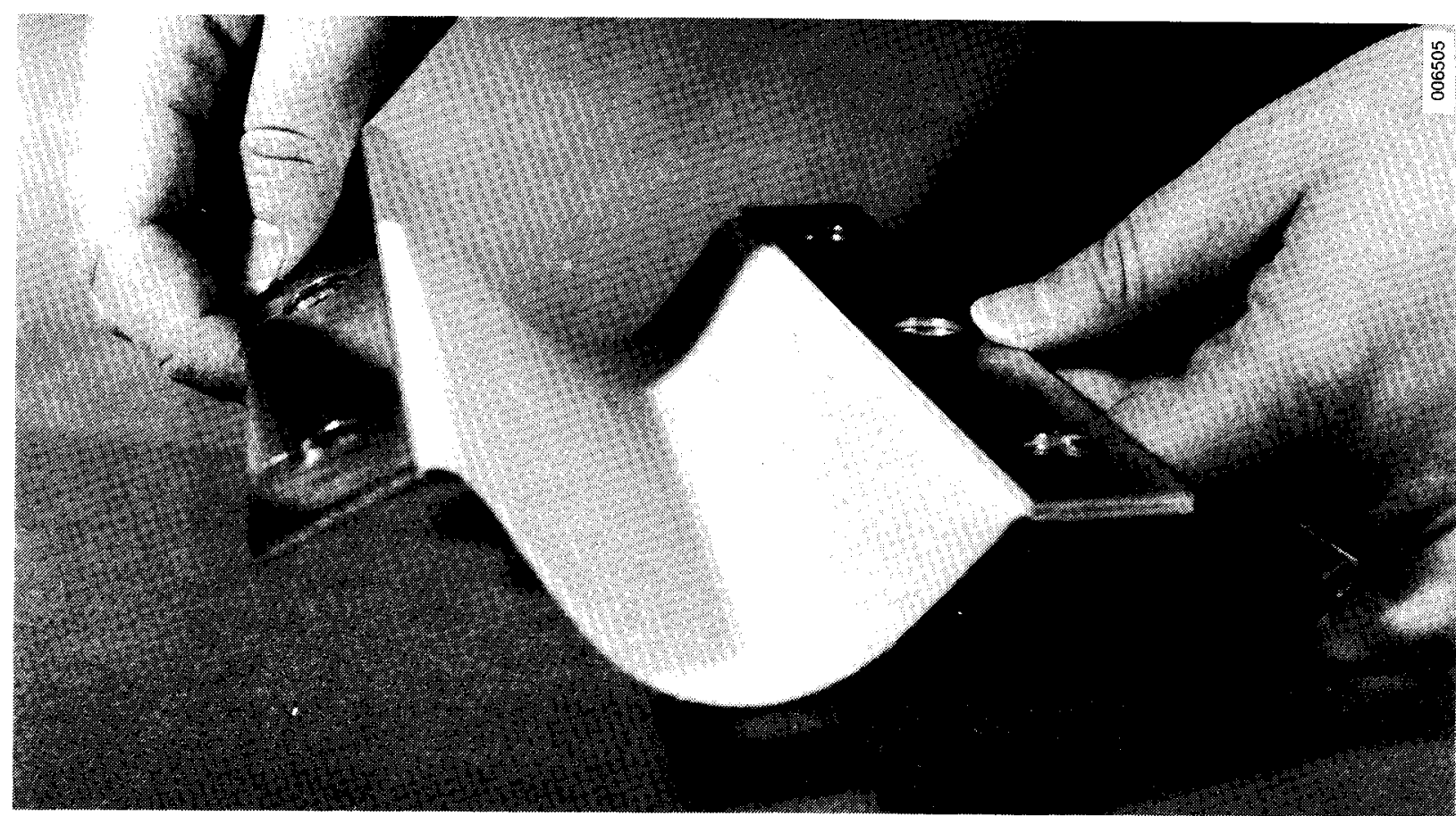

Figure 3-1. A Silica-Gel-Coated Polyester Tape with Attached Spacers (used in a parallel-plate dehumidifier)

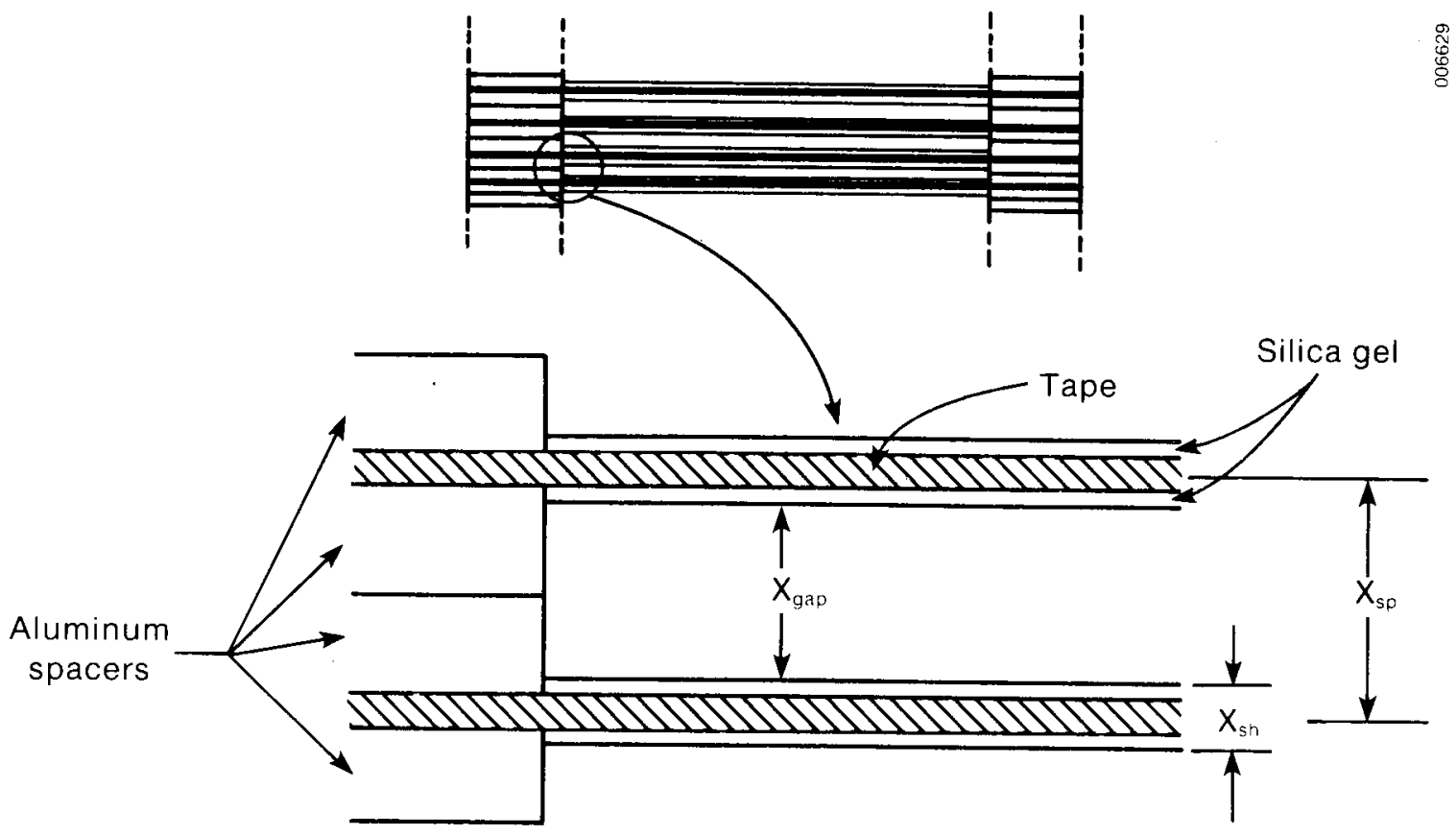

Figure 3-2. Paralle1-P1ate Test Article (cross-sectional view) 


\section{SEPI 絭}

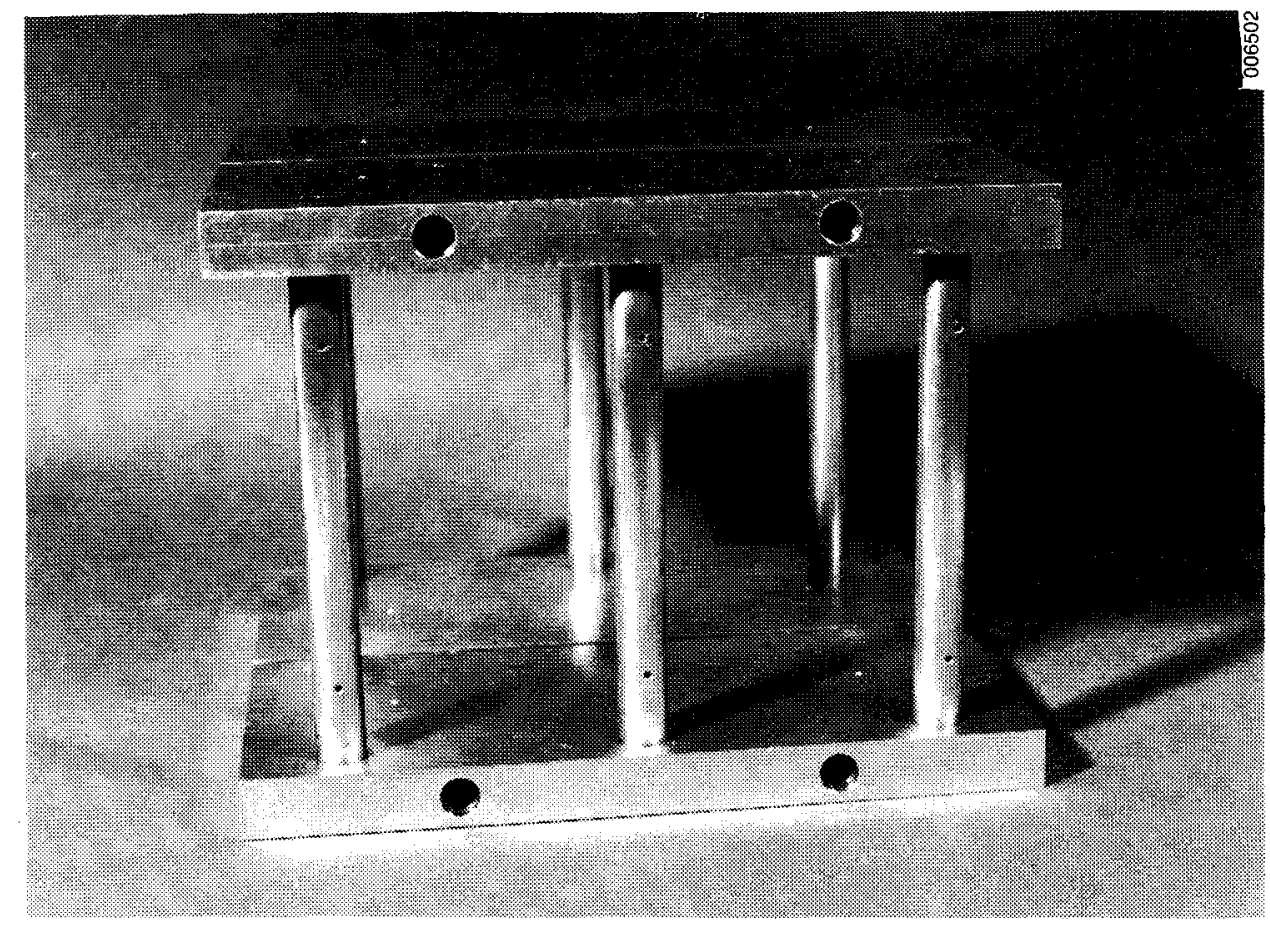

Figure 3-3. Supporting Frame of the Parallel-Plate Test Article

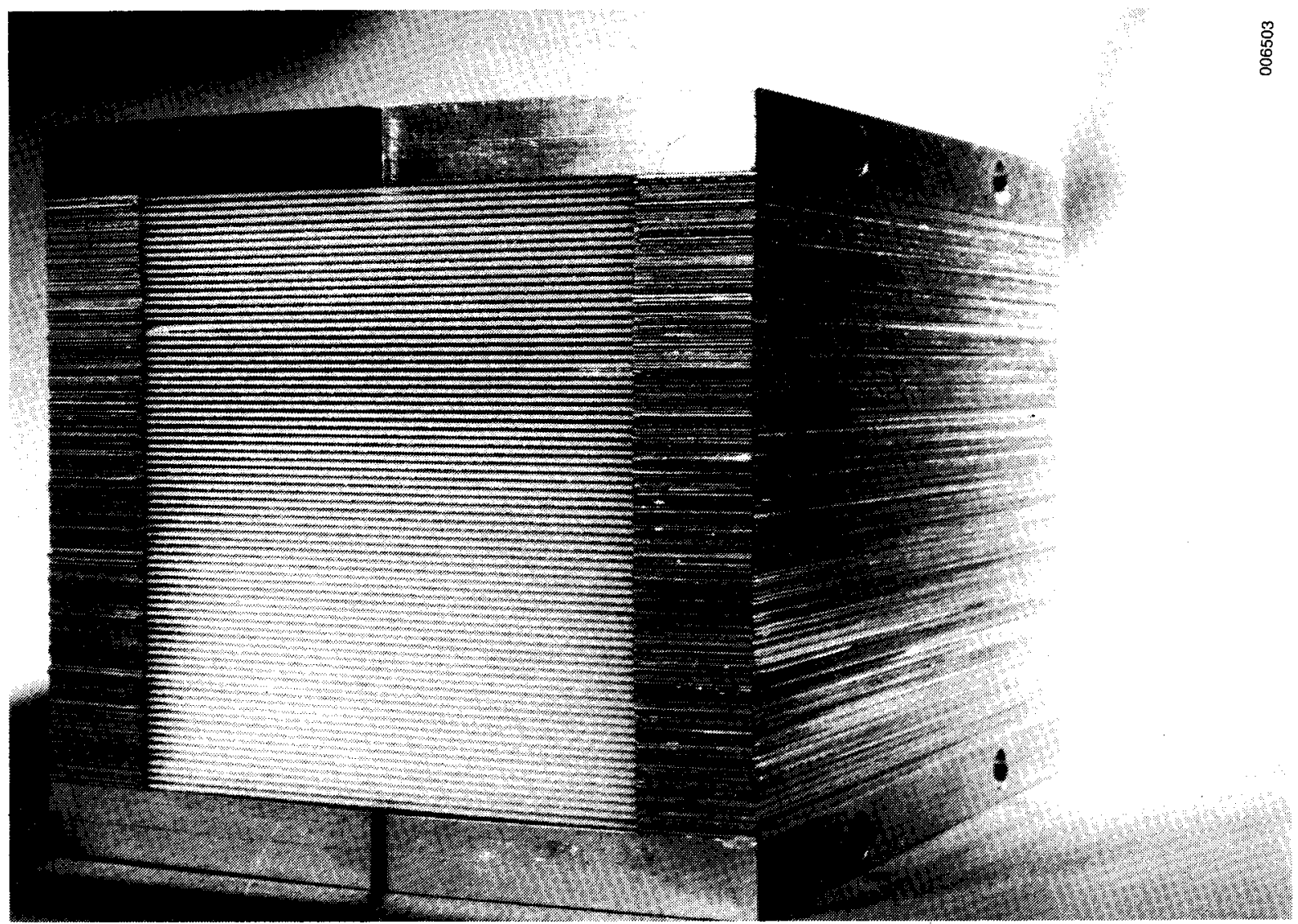

Figure 3-4. Finished Parallel-Plate Dehumidifier Test Article 


\section{SEPI}

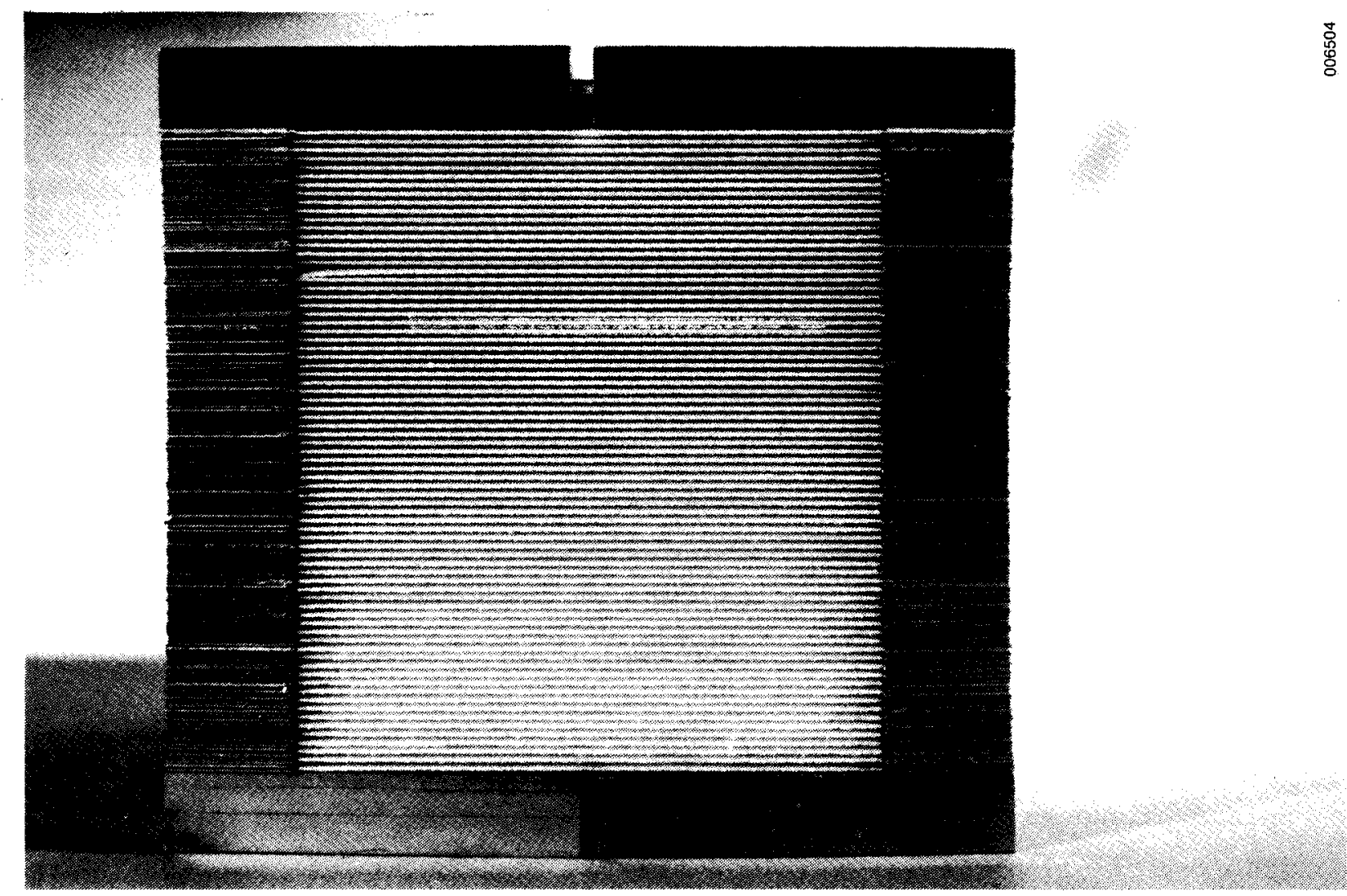

Figure 3-5. Cross-Sectional View of the Parallel-Plate Test Article. Note the highly uniform spacing.

Figures 3-4 and 3-5 show the highly uniform spacing in the finished test article. Spacers with different thicknesses can be inserted between sheets to provide different flow gaps. The specifications of this test article are given in Table $3-1$. 
Table 3-1. Specification of the Parallel-Plate Test Article Dehumidifier

\begin{tabular}{|c|c|}
\hline Desiccant type & Silica gel, Davison Grade 11 \\
\hline Particle size $\left(d_{p}\right)$ & $\begin{array}{l}\text { 177-297 } \mu \mathrm{m}(\text { mesh size } 50 \text { to } 80) \\
\text { Average: } 237 \mu \mathrm{m}\end{array}$ \\
\hline Particle density $\left(\rho_{p}\right)$ & $1131 \mathrm{~kg} / \mathrm{m}^{3}$ \\
\hline Specific heat of silica gel ( $\left.c_{g e l}\right)$ & $921 \mathrm{~J} / \mathrm{kg} \mathrm{K}$ \\
\hline Tape type & $\begin{array}{l}\text { AR Clad } 5190, \text { Adhesive Research, } \\
\text { Inc. (Double-sided polyester } \\
\text { tape with acrylic adhesive) }\end{array}$ \\
\hline Specific heat of tape $\left(c_{\text {tape }}\right)$ & $1172 \mathrm{~J} / \mathrm{kg} \mathrm{K}$ \\
\hline Tape thickness & $76 \mu \mathrm{m}$ \\
\hline Adhesive thickness (each side) & $25 \mu \mathrm{m}$ \\
\hline $\begin{array}{l}\text { Sheet thickness }\left(X_{{ }_{s h}}\right) \\
\text { (silica-gel-coated tape, both sides) }\end{array}$ & $\begin{array}{l}430-670 \mu \mathrm{m} \\
\text { Average: } 550 \mu \mathrm{m}\end{array}$ \\
\hline Center-to-center sheet spacing $\left(\mathrm{x}_{\mathrm{sp}}\right)$ & $1664 \mu \mathrm{m}$ \\
\hline Spacer thickness & $794 \mu \mathrm{m}$ (aluminum) \\
\hline Flow gap $\left(x_{\text {gap }}\right)$ & $\begin{array}{l}994 \text { to } 1234 \mu \mathrm{m} \\
\text { Average: } 1114 \mu \mathrm{m}\end{array}$ \\
\hline $\begin{array}{l}\text { Silica gel density on tape, } \\
\text { both sides, }{ }^{M} D\end{array}$ & $0.279 \mathrm{~kg} / \mathrm{m}^{2}$ \\
\hline Dimensions of the dehumidifier part & $\begin{array}{l}0.117 \times 0.126 \times 0.203 \mathrm{~m} \\
\text { (width } \times \text { height } \times \text { length) }\end{array}$ \\
\hline Dimensions of the test article & $\begin{array}{l}0.169 \times 0.161 \times 0.203 \mathrm{~m} \\
\text { (width } \times \text { height } \times 1 \text { length) }\end{array}$ \\
\hline Surface area/volume (a) & $12021 / \mathrm{m}$ \\
\hline Tape to desiccant ratio (TDR) & $\begin{array}{l}0.350 \mathrm{~kg} \text { of tape } / \mathrm{kg} \text { of } \mathrm{dry} \\
\text { desiccant }\end{array}$ \\
\hline Desiccant bed density $\left(\rho_{b}\right)$ & $\begin{array}{l}176.6 \mathrm{~kg} \text { of dry desiccant } / \mathrm{m}^{3} \text { of } \\
\text { bed }\end{array}$ \\
\hline
\end{tabular}




\subsection{EXPERIMENTAL PROCEDURE}

To obtain single-blow data, first bring the desiccant in the test article up to initial desired conditions, and then introduce process air prepared at specified conditions to the test article. This simulates a step change in the inlet conditions. The inlet and outlet air conditions (temperature and humidity) are monitored and recorded with time, and the data are collected. The test section is insulated to simulate adiabatic operation. The following is a step-by-step procedure for performing the experiments (see Figure 2-2). Each test consists of preparation and process steps. Depending on the desired initial and inlet conditions, the process step of one test can be the preparation step for the next test.

\subsection{Preparation of The Test Article}

1. Close BV1 and GV. Open BV2 and switch the three-way valve to monitor the dew point temperature of the bypass.

2. Turn on the blower.

3. Adjust $D$ to the desired flow rate.

4. Set temperature at the temperature controller and turn on $4.1-\mathrm{kW}$ heater (if heating is necessary).

5. Turn on the boiler and set the humidity (if humidification is necessary).

6. Activate the data acquisition program. When desired temperature or humidity is reached, adjust D again.

7. Open BV1 and GV. Close BV2 to introduce conditioned air to the test article. Switch the three-way valve to monitor the dew point temperature of the inlet process air.

8. Monitor inlet and outlet conditions. When the conditions are the same, the desiccant in the test article has reached equilibrium with the process air. Note the air conditions for a period of five minutes.

9. Open BV2. Close BVI and GV. Switch the three-way valve to bypass.

10. Turn off the boiler, the heater, and finally the blower.

\subsection{Process (Adsorption/Desorption)}

1. Make sure that BVI and GV are closed and BV2 is open. Switch the three-way valve to monitor the dew point temperature of the bypass.

2. Turn on the blower (the desired pully combination and motor speed are al ready set.

3. Adjust $D$ to desired flow rate.

4. Set the temperature on the controller and turn on the heater.

5. Turn on the humidifier and set the humidity. 
6. Activate the data acquisition program. When desired temperature and humdity are reached, adjust $D$.

7. Open BV1, and simultaneously open GV and close BV2 to start the singleblow experiment. Activate the data collection. Switch the three-way valve to monitor the dew point temperature of the inlet process air.

8. Record inlet and outlet air temperatures and humidities and pressure drops to measure the transient response of the test dehumidifier. Carry out the experiment until equilibrium is reached.

9. Open BV2. Close BV1 and GV.

10. Turn off the boiler, the heater, and finally the blower. 


\subsection{HEAT AND MASS TRANSFER MODELS}

\subsection{Governing Equations}

The purpose of this study is to use the available heat and mass transfer models for other geometries than parallel plate and extend them to the geometry that is under investigation here. Among the computer codes available at SERI (DESSIM [1], MOSHMX [20], and DESICCANT [14]), DESICCANT has the capability of simulating transient performance of a dehumidifier by both lumped-capacitance and solid-side-resistance models in which we are interested. DESICCANT was originally developed and validated for packed beds, and thus needs to be modified for parallel-plate geometry. The methodology for developing differential equations used in DESICCANT that govern the adiabatic transient response of a desiccant bed can be found in Pesaran [14]. The assumptions made for these governing equations are: axial and radial diffusion and conduction and the storage terms in the gas phase are negligible; the particles are isothermal at each axial location; transfer coefficients are constant; and axial diffusion and conduction in the solid phase are negligible. In this section the governing equations developed for DESICCANT are presented.

The dimensionless form of the governing equations for the lumped-capacitance model are as follows:

mass balance in the gas phase:

$$
\frac{\partial m_{1, e}}{\partial z^{\frac{1}{x}}}=N_{t u, e f f}\left(m_{1, s}-m_{1, e}\right)\left(1-m_{1, e}\right) \text {, }
$$

mass balance in the solid phase:

$$
\frac{\partial W_{\text {avg }}}{\partial t^{*}}=-\frac{N_{t u, e f f}}{D A R}\left(m_{1, s}-m_{1, e}\right),
$$

energy balance in the gas phase:

$$
\frac{\partial T_{e}}{\partial z^{*}}=-N_{t u, e f f}\left[L e_{e f f}+r_{1}\left(m_{1, s}-m_{1, e}\right)\right]\left(T_{e}-T_{s}\right),
$$

and energy balance in the solid phase:

$$
\frac{\partial T_{s}}{\partial t^{\prime t}}=\frac{N_{t u, e f f}}{r_{b} \text { DAR }}\left[L_{e f f}\left(T_{e}-T_{s}\right)-\left(H_{a d s} / c_{p, e}\right)\left(m_{1, s}-m_{1, e}\right)\right] \text {. }
$$

The above equations are coupled through the equilibrium isotherm relation

$$
\mathrm{m}_{1, \mathrm{~s}}=\mathrm{g}\left[\mathrm{W}_{\mathrm{avg}}, \mathrm{T}_{\mathrm{s}}, \mathrm{P}\right] \text {. }
$$

For the definition of the above parameters, see the Nomenclature. Note that in the lumped-capacitance model the solid phase at each cross section is treated as a lump with no concentration gradient in the solid phase perpendicular to the flow. The transfer unit $\mathrm{N}_{\text {tu, eff }}$ depends on the effective mass transfer coefficient $K_{G}$, eff through the relation

$$
\mathrm{N}_{\mathrm{tu}, \text { eff }}=\frac{\mathrm{K}_{\mathrm{G}, \text { eff } \mathrm{PL}}}{\dot{\mathrm{m}}_{\mathrm{G}}} \text {, }
$$


where $\mathrm{p}$ is the perimeter of the desiccant bed. The coefficient $\mathrm{K}_{\mathrm{G}}$ eff depends on the magnitude of both gas-side and solid-side mass transfer coefficients. However, since the driving potentials in the gas and solid phases have different units, $K_{G}$ off cannot be easily expressed in terms of gas- and solidside transfer coefficients. For the small particles of silica gel used for this study the solid-side resistance can be considered a fraction of gas-side resistance [9], and thus one can write

$$
\mathrm{K}_{\mathrm{G}, \text { eff }}=\frac{\mathrm{K}_{\mathrm{G}}}{\alpha} \text {, }
$$

where $K_{G}$ is the pure gas-side mass transfer coefficient in the passages and $\alpha$ is a number greater than unity that depends on the particle size and diffusivity of $\mathrm{H}_{2} \mathrm{O}$ into the desiccant particles. To obtain the relation between effective Lewis number and $\alpha$, the anology between heat and mass transfer for parallel-plate geometry is used

$$
\text { Le }=(\mathrm{Sc} / \mathrm{Pr})=\frac{\mathrm{h}_{\mathrm{c}}}{\mathrm{K}_{\mathrm{G}} \mathrm{c}_{\mathrm{p}, e}} \text {, }
$$

and

$$
\mathrm{Le}_{\text {eff }}=\frac{\mathrm{h}_{\mathrm{c}}}{\mathrm{K}_{\mathrm{G}, \text { eff }}{ }^{\mathrm{c} p, e}} \text {. }
$$

Dividing Eq. 5-9 by Eq. 5-8 and substituting Eq. 5-7 one can obtain

$$
\alpha=\frac{\text { Le eff }}{\text { Le }} \text {. }
$$

For silica-gel-coated parallel-plate geometry the specific heat of the bed $c_{b}$ depends on the specific heat of moist silica gel and the polyester tape through the relation

$$
c_{b}=w_{\text {avg }} c_{1}+c_{\text {desiccant }}+c_{\text {tape }} \text { TDR , }
$$

where TDR is the ratio of tape mass to dry desiccant mass.

The model with solid-side resistance in the DESICCANT code assumes that the particles are spherical, that there is a concentration gradient across each particle and that water molecules diffuse into microporous silica gel particles by surface diffusion [14]. Assuming radial symmetry for spherical silica gel particles, the dimensionless mass balance equation in the solid phase becomes

$$
\frac{\partial W}{\partial t^{*}}=\frac{1}{r^{* 2}} \frac{\partial}{\partial r^{*}}\left(D^{*} r^{* 2} \frac{\partial W}{\partial r^{*}}\right)
$$

with boundary conditions:

at the center

$$
\left.\frac{\partial W}{\partial r^{*}}\right|_{r *=0}=0
$$

and at the surface

$$
-\left.\beta \frac{\partial W}{\partial \mathbf{r}^{*}}\right|_{\mathbf{r}^{*}=1}=\left(\mathrm{m}_{1, \mathrm{~s}}-\mathrm{m}_{1, \mathrm{e}}\right) \text {. }
$$

The above set of equations replaces Eq. 5-2 of the lumped-capacitance model. The other governing equations of the model with solid-side resistance are the 
same as Eqs. 5-1, 5-3, and 5-4 of the lumped-capacitance model if $\mathrm{N}_{\text {tu, eff }}$ and Le eff are replaced with $N_{t u}$ and Le, respectively. The transfer unit $N_{\text {tu }}$ depends on the true gas-side mass transfer coefficient $K_{G}$ through the relation

$$
\mathrm{N}_{\mathrm{tu}}=\frac{\mathrm{K}_{\mathrm{G}} \mathrm{pL}}{\mathrm{t}_{\mathrm{G}}}
$$

The governing equations are coupled through the equilibrium isotherm at the surface of desiccant particles

$$
\mathrm{m}_{1, \mathrm{~s}}=\mathrm{g}\left[\mathrm{W}\left(\mathrm{r}^{*}=1\right), \mathrm{T}_{\mathrm{s}}, \mathrm{P}\right] \text {. }
$$

An average gel water content is required for energy conservation equations, which for a spherical particle is

$$
w_{\text {avg }}=3 \int_{0}^{1} r^{* 2} w d r^{*} \text {. }
$$

Note that part of a particle is blocked by the adhesive that bonds the particle to the wall of passages and thus the diffusion of $\mathrm{H}_{2} \mathrm{O}$ into the particle is not symmetrical. However, as a first approximation we have assumed that the diffusion mechanism is symmetrical.

The governing equations (Eqs. 5-1, 5-2, 5-3,5-4, 5-5 for the lumpedcapacitance model and Eqs. 5-1, 5-3, 5-4, 5-12, 5-14, 5-15 for the solid-sideresistance model) were solved for a step change in the inlet conditions using finite difference methods [14]. The inlet and initial condition for solving the equations are:

inlet conditions

$$
\begin{aligned}
T\left(t^{*}, z^{*}\right. & =0)=T_{i n}, \\
\left.m_{1, e^{(t *}, z^{*}}=0\right) & =m_{1, i n},
\end{aligned}
$$

and initial conditions

$$
\begin{aligned}
& T\left(t^{*}=0, z^{*}\right)=T_{0} \\
& W\left(t^{*}=0, z^{*}\right)=W_{0} .
\end{aligned}
$$

The details of the numerical procedure and the associated computer program DESICCANT can be found in Pesaran [14]. The results of solving DESICCANT, which are in terms of mass fraction $\mathrm{m}_{1}$, can be easily converted to an absolute humidity ratio for comparison with experimental results using the relation $\mathrm{w}=\mathrm{m} /(1-\mathrm{m})$.

\subsection{Auxiliary Equations}

To obtain numerical predictions several parameters that specify characteristics of the desiccant, the bed, and the flow must be known. If $x_{s h}$ is the thickness of a sheet of silica-gel-coated tape and $x_{s p}$ is the center-to-center spacing of the sheets, then the air gap of each channel from Figure $3-2$ is

$$
x_{\text {gap }}=x_{s p}-x_{s h}
$$


and thus the hydraulic diameter of each channel is

$$
d_{h}=2 x_{\text {gap }}=2\left(x_{s p}-x_{s h}\right) \text {. }
$$

The number of sheets per unit height of the matrix is $1 / x_{s p}$ and the surface area per unit volume of the dehumidifier is

$$
a=\frac{2}{x_{s p}} \text {. }
$$

The density of desiccant in the matrix $o_{b}$ is

$$
\rho_{\mathrm{b}}=\frac{\mathrm{M}_{\mathrm{D}}}{\mathrm{X}_{\mathrm{sp}}},
$$

where $M_{D}$ is the dry mass of desiccant per unit area of sheets. Then the desiccant-to-air ratio when a mass flow rate of $\dot{m}_{G}$ passes through the bed during experimental time $\tau$ is

$$
\operatorname{DAR}=\frac{\rho_{b} A L}{\mathrm{H}_{G}{ }^{\tau}},
$$

where $A$ is the frontal area of the dehumidifier matrix. The porosity of the matrix is

$$
\varepsilon=\frac{\left(x_{s p}-x_{s h}\right)}{x_{s p}} .
$$

Using this porosity one can find the velocity in a channel from superficial air velocity $V_{\text {sup }}$

$$
\mathrm{V}=\frac{\mathrm{V}_{\text {sup }}}{\varepsilon} \text {, }
$$

where

$$
\mathrm{V}_{\text {sup }}=\frac{\mathrm{m}_{\mathrm{G}}}{\rho \mathrm{A}} \text {. }
$$

The Reynolds number in a channel is

$$
\operatorname{Re}=\frac{V d_{h}}{v} \text {. }
$$

Gas-side heat or mass transfer coefficients, $h_{C}$ or $K_{G}$, can be estimated from a theoretical Nusselt number of fully developed laminar flow between parallel plates [25] for the cases of constant wall temperature or concentration $(\mathrm{Nu}=7.54)$ and constant heat or mass flux $(\mathrm{Nu}=8.325)$. Although the sorption process does not fit either of these limits, it is closer to the constant heat or mass flux cases [26]. The gas-side heat transfer coefficient is

$$
\mathrm{h}_{\mathrm{c}}=\frac{\mathrm{kNu}}{\mathrm{d}_{\mathrm{h}}} \text {, }
$$

where $k$ is humid air conductivity. The gas-side mass transfer coefficient, using an analogy between heat and mass transfer for parallel plate, is

$$
\mathrm{K}_{\mathrm{G}}=\frac{\mathrm{h}_{\mathrm{c}}}{\mathrm{c}_{\mathrm{p}, \mathrm{e}^{\mathrm{Le}}}}
$$

The overall mass transfer coefficient is lower than the gas-side transfer coefficient because of resistance of moisture diffusion within the desiccant particles 


$$
K_{G, e f f}=\frac{K_{G}}{a}=K_{G} \frac{L e}{L e_{e f f}}=\frac{h_{c}}{c_{p, e} \operatorname{Leff}_{e f}} .
$$

The number of transfer units can be estimated from

$$
N_{t u}=\frac{K_{G} P L}{m_{G}}=\frac{K_{G} a A L}{m_{G}} \text {, }
$$

or

$$
\mathrm{N}_{\mathrm{tu}, \text { eff }}=\frac{\mathrm{K}_{\mathrm{G}, \text { eff }} \mathrm{aAL}}{\mathrm{h}_{\mathrm{G}}} \text {. }
$$

Grade 11, Davison, silica gel used in this study has properties similar to Grade $40 \mathrm{gel}$. The following polynomial [14] that fits the manufacturer's vapor pressure data on Grade 40 is used to represent the equilibrium isotherm of the desiccant:

$$
R H=0.0078-0.05759 w+24.16554 W^{2}-124.478 W^{3}+204.226 W^{4}
$$

where $R H$ is relative humidity ratio, $P_{\text {vapor }} / \mathrm{P}_{\text {sat }}$. Preliminary results have shown that the adhesive can reduce the capacity of the gel only up to $10 \%$. The heat of adsorption is estimated from the following relations [14]:

$$
\begin{aligned}
& \mathrm{H}_{\mathrm{ads}}=-12400 \mathrm{~W}+3500 \mathrm{~W}<0.05 \\
& \mathrm{H}_{\mathrm{ads}}=-1400 \mathrm{~W}+2950 \mathrm{~W} \geq 0.05
\end{aligned}
$$

The dominant mechanism of moisture diffusion within microporous silica gel particles is surface diffusion, and a correlation for this surface diffusivity is given in Pesaran [14], which is

$$
D=1.6 \times 10^{-6} \exp \left[-0.947 \times 10^{-3}\left(\mathrm{H}_{\mathrm{ads}} /(\mathrm{T}+273.1 .5)\right] .\right.
$$

\subsection{Pressure Drop Analysis}

Assuming fully developed laminar flow in the channels, the pressure drop across the dehumidifier matrix for constant property is [23]

$$
\Delta \mathrm{P}=\frac{\rho \mathrm{V}^{2}}{2}\left[\mathrm{~K}+4 \mathrm{f} \frac{\mathrm{L}}{\mathrm{d}_{\mathrm{h}}}\right],
$$

where $f$ is the Fanning friction factor and for rectangular passages is given by [24]

$$
f=\frac{24}{\operatorname{Re}} \frac{1}{\left(1+x_{g a p} / B\right)^{2}\left(1-0.639249 x_{\text {gap }} / B\right)}
$$

and $\mathrm{K}=0.686$.

The measured pressure drop is slightly different than the pressure drop across the dehumidifier matrix because the pressure taps are positioned away from the matrix. The correction for this configuration that is used here is recommended by Maclaine-cross and Ambrose [23]. The pressure drop between the inlet pressure tap, and the entrance of the dehumidifier matrix is [23]

$$
\Delta P_{\text {in }}=\frac{\rho V^{2}}{2}\left(1-\left(A_{e} / A_{d}\right)^{2}\right) \text {, }
$$


where $A_{e}$ is the minimum free-flow area of the dehumidifier passages and $A_{d}$ is the cross-sectional area of the test section at the inlet pressure tap. Equation 5-35 is obtained using Bernoulli's equation and the continuity at the entrance of the dehumidifier. The pressure drop between the exit of the dehumidifier and outlet pressure tap is [23]

$$
\Delta \mathrm{P}_{\text {out }}=\frac{\rho V^{2}}{2}\left(2\left(\mathrm{~A}_{\mathrm{e}} / \mathrm{A}\right)^{2}-2.4 \mathrm{~A}_{\mathrm{e}} / \mathrm{A}\right) \text {, }
$$

where $A$ is the frontal area of the dehumidifier matrix. Eq. 5-36 is obtained using conservation of momentum and continuity at the exit of the matrix assuming a parabolic velocity profile at the exit of the dehumidifier and a uniform velocity at the outlet pressure tap.

The predicted pressure drop between the inlet and outlet pressure taps can be estimated using Eqs. 5-33, 5-35, and 5-36,

$$
\Delta \mathrm{P}_{\text {pre }}=\Delta \mathrm{P}_{\text {in }}+\Delta \mathrm{P}+\Delta \mathrm{P}_{\text {out }} \cdot
$$

Then $\Delta \mathrm{P}_{\text {pre }}$ can be directly compared with the measured pressure drop $\Delta \mathrm{P}_{\exp }$. The experimental friction factor $f_{\exp }$ can be obtained from

$$
f_{\exp }=\frac{d_{h}}{4 L}\left[\frac{\left(\Delta P_{\text {exp }}-\Delta P_{\text {in }}-\Delta P_{\text {out }}\right)}{\rho V^{2} / 2}-K\right] \text {. }
$$

and can be compared with the predicted friction factor from Eq. 5-34. 


\subsection{RESULTS AND DISCUSSION}

The major facus of this project was on the design, fabrication, instrumentation, and shakedown of the test facility. Therefore only a limited number of experiments under adiabatic conditions were performed and compared with model predictions. Table 6-1 summarizes the conditions of the tests performed. The specifications of the test dehumidifier were given in Table 3-1. The experimental results were obtained after a step change was introduced in the air inlet conditions to the dehumidifier. Desired uniform conditions were established before the step change. The outlet air temperature and humidity as a function of time and pressure drop across the dehumidifier were measured during each experiment. Figures 6-1 to 6-4 show the experimental results as well as model predictions. The experimental data were collected in voltages, converted to engineering units, and then plotted by an HP9845A computer. The model predictions using DESICCANT code were obtained from a mainframe computer (Cyber 760 at NOAA), transferred to the HP9845A, and finally plotted along with the experimental results. Inlet and outlet conditions are shown in Table 6-1 for both measured and predicted results as a function of time.

Experiments 1 (Figure 6-1) and 4 (Figure 6-3) are adsorption cases that were performed by the humidification of the process air using the boilerhumidifier. The variation of the inlet humidity $( \pm 0.004 \mathrm{~kg} / \mathrm{kg})$ is 1 arge, which can be caused by a fluctuation of supply pressure in the steam boiler and poor control of steam flow rate by the electronic controller valve. We can observe that the outlet humidity follows the fluctuation of the inlet humidity and that the fluctuation in the outlet air temperature is sensitive to inlet air humidity. Since the DESICCANT code at the present time is set up for a constant step change in the inlet conditions, average inlet conditions are used for obtaining the predictions.

Table 6-1. Experimental Parameters

\begin{tabular}{|c|c|c|c|c|c|c|c|c|c|}
\hline \multirow{2}{*}{$\begin{array}{l}\text { Run } \\
\text { No. }\end{array}$} & \multirow{2}{*}{ Process ${ }^{a}$} & \multicolumn{2}{|c|}{$\begin{array}{c}\text { Initial } \\
\text { Conditions }\end{array}$} & \multicolumn{2}{|c|}{$\begin{array}{l}\text { Average Inlet } \\
\text { Conditions }\end{array}$} & \multicolumn{2}{|c|}{$\begin{array}{l}\text { Average Elow } \\
\text { Conditions }\end{array}$} & \multirow[b]{2}{*}{$\begin{array}{c}\Delta P_{\exp } \\
(\mathrm{Pa})\end{array}$} & \multirow{2}{*}{$N_{t u}^{c}$} \\
\hline & & $\begin{array}{l}\mathrm{T}_{0} \\
\left({ }^{\circ} \mathrm{C}\right)\end{array}$ & $\begin{array}{c}W_{0}{ }^{b} \\
(\mathrm{~kg} / \mathrm{kg})\end{array}$ & $\begin{array}{l}\mathrm{T}_{\mathrm{in}} \\
\left({ }^{\circ} \mathrm{C}\right)\end{array}$ & $\begin{array}{c}\mathrm{w}_{\text {in }} \\
(\mathrm{kg} / \mathrm{kg})\end{array}$ & $\begin{array}{c}\dot{\mathrm{m}}_{\mathrm{G}} \\
(\mathrm{g} / \mathrm{s})\end{array}$ & $\begin{array}{c}V \\
(\mathrm{~m} / \mathrm{s})\end{array}$ & & \\
\hline 1 & $A D$ & 24.6 & 0.02 & 30.0 & 0.0144 & 20.5 & 2.22 & 95 & 12.67 \\
\hline 3 & $\mathrm{DE}$ & 25.2 & 0.14 & 56.5 & 0.0084 & 18.9 & 2.19 & 90 & 14.74 \\
\hline 4 & $A D$ & 21.5 & 0.04 & 25.5 & 0.0125 & 18.1 & 1.89 & 80 & 14.53 \\
\hline 5 & $\mathrm{DE}$ & 24.2 & 0.23 & 38.8 & 0.0670 & 16.2 & 1.79 & 68 & 16.49 \\
\hline
\end{tabular}

$a_{A D}=$ Adsorption, $D E=$ Desorption

${ }^{b}$ Calculated using Eq. 5-30

$\mathrm{C}_{\text {Based on a Nuselt number of } 8.235}$ 


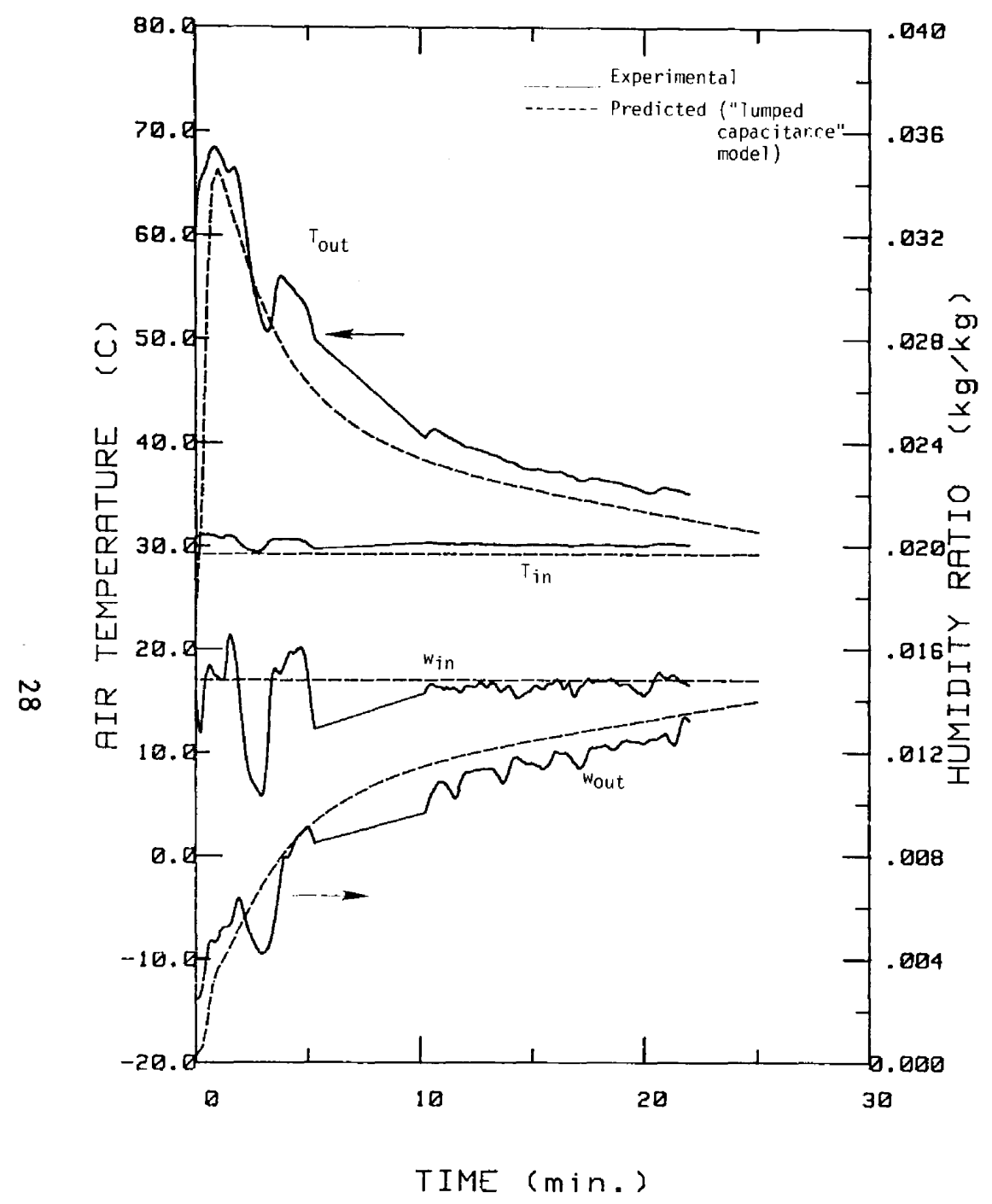

Figure 6-1. Comparison of Experimental and Predicted Results for Exp. 1

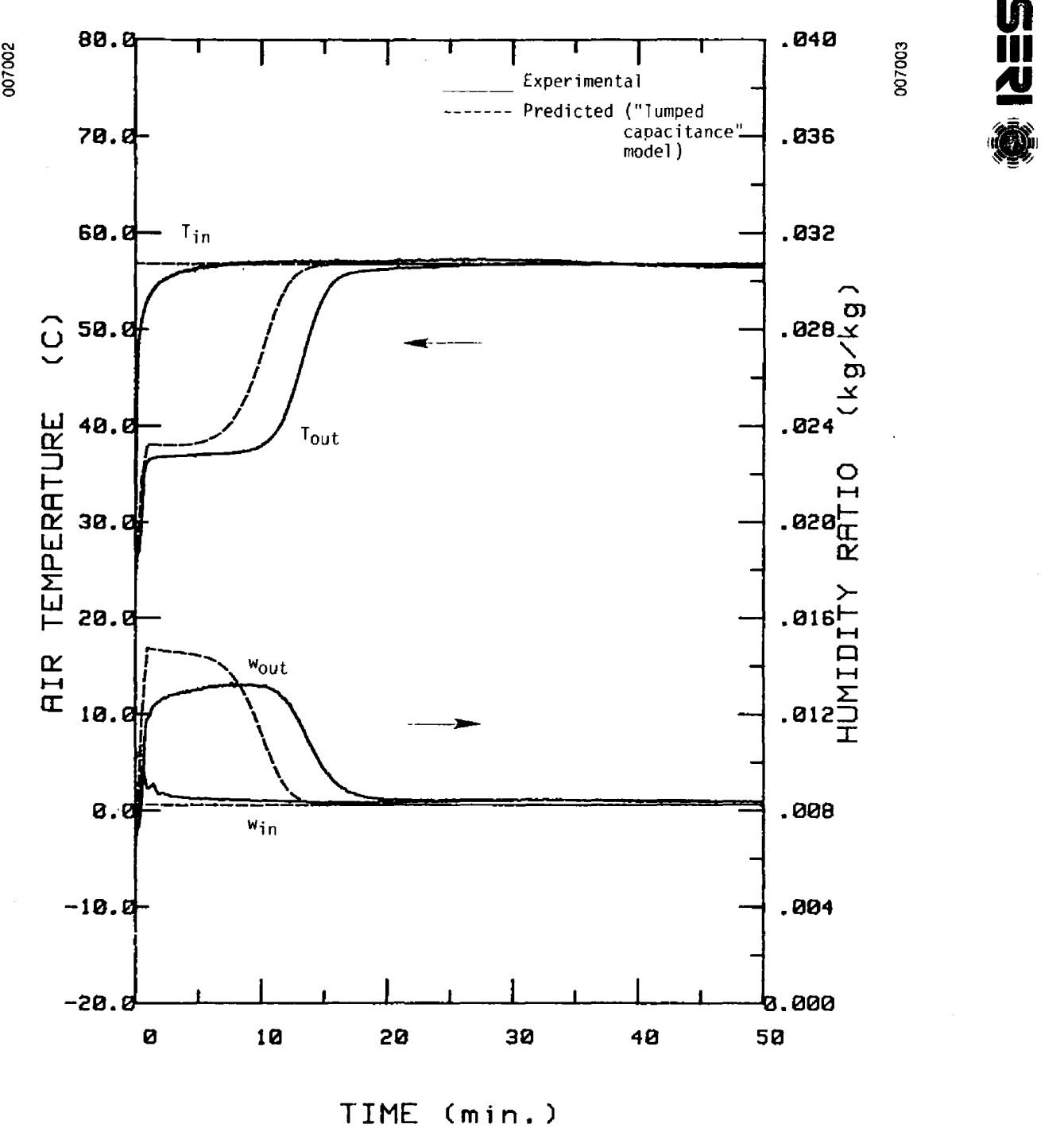

Figure 6-2. Comparison of Experimental and Predicted Results for Exp. 3 


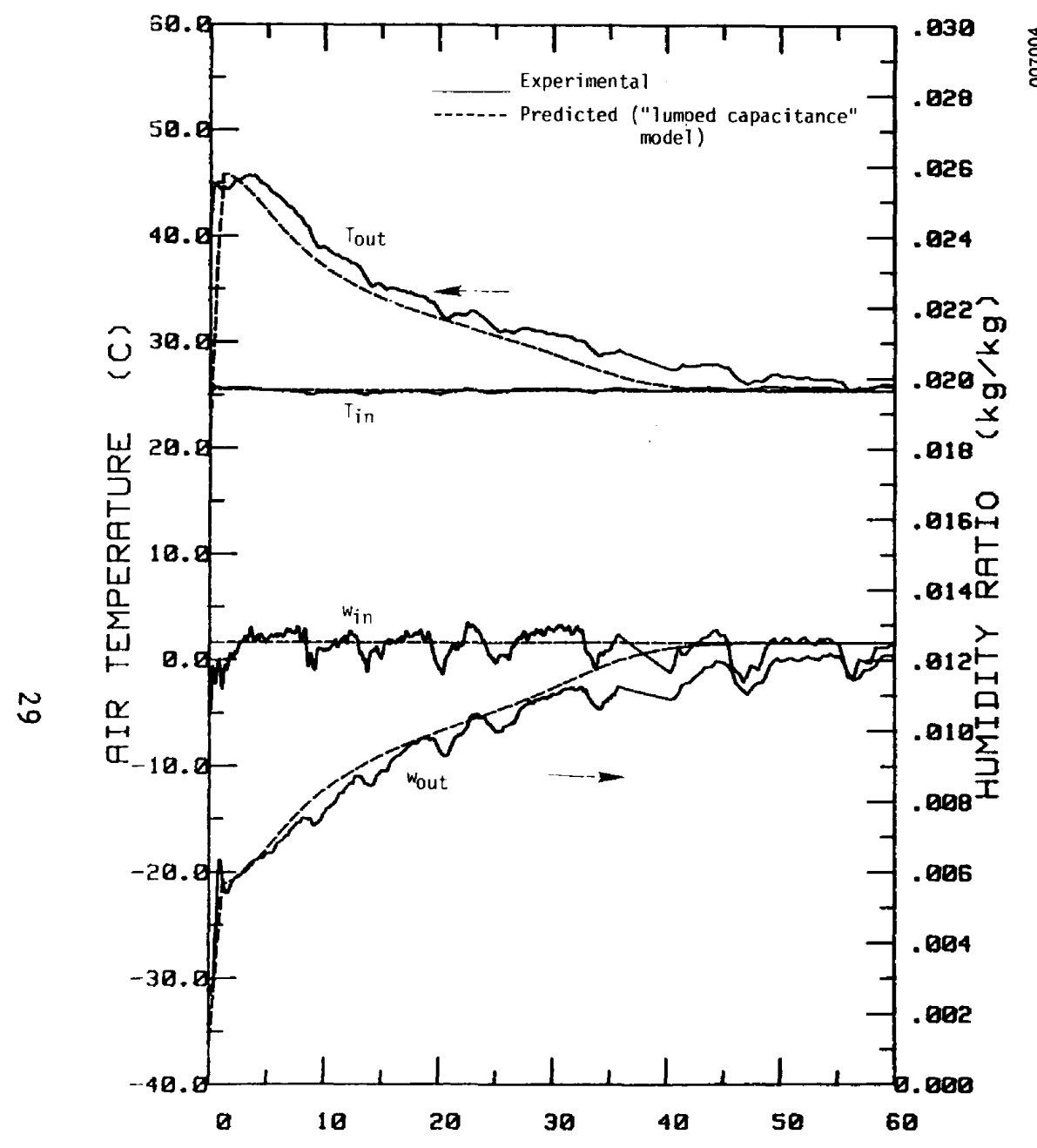

TIME (min.)

Figure 6-3. Comparison of Experimental and Predicted Results for Exp. 4

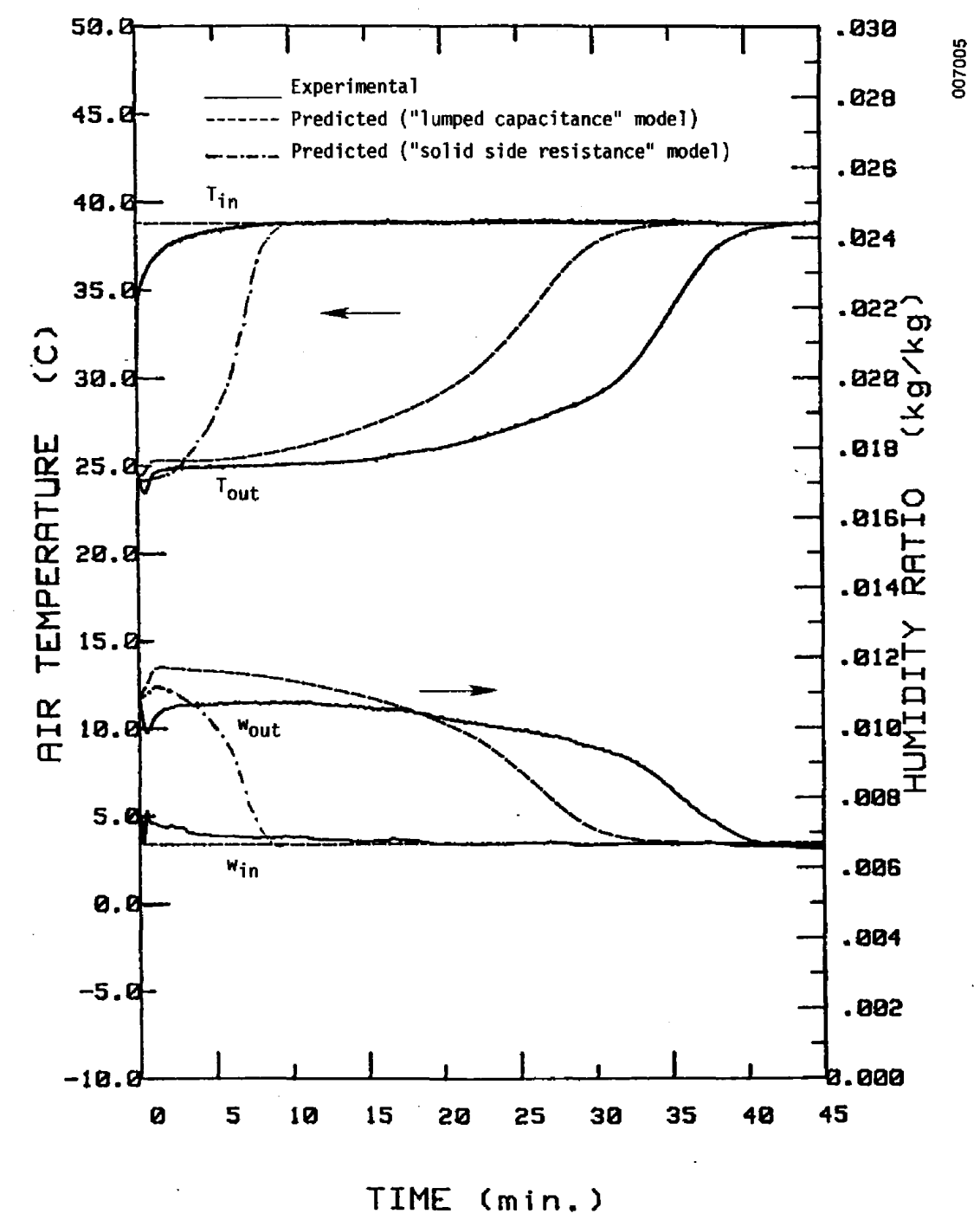

Figure 6-4. Comparison of Experimental and Predicted Results for Exp. 5 
Experiments 3 (Figure 6-2) and 5 (Figure 6-4) are desorption cases that were performed by heating the process air without any humidification. The fluctuation of the inlet air temperature is small $\left( \pm 0.3^{\circ} \mathrm{C}\right)$. This low initial inlet air temperature observed in experiments 3 and 5 is a result of the thermal mass of the metal duct between the bypass test section and the gate valve that initially cools the air temperature. The small fluctuation in the inlet air humidity observed in experiments 3 and 4 is caused by a variation of the ambient air humidity.

Predicted results using the 1 umped-capacitance model and the model with solidside-resistance that were solved by the DESICCANT code were obtained. For the solid-side-resistance model, predicted results were unstable unless a large number of integration points in three coordinates ( $\left.r^{*}, z^{*}, t^{*}\right)$ were used; it appeared that the conditions of these experiments (mainly small particle size) caused this instability. A higher number of integration points required an excessive amount of computation time and computer cost.

The predicted results for experiment 5 using both models were compared with experimental results (Figure 6-4). The predictions of the lumped-capacitance model agree better with experimental results than the predictions of the solid-side-resistance model. One may have expected that the model with solidside resistance would agree better with experimental data. For example, in the case of packed beds with larger particle sizes the predictions of the solid-side-resistance model agreed better with experimental data [14]. One possible explanation for the unexpected result could be that the assumption of symmetrical diffusion, of $\mathrm{H}_{2} \mathrm{O}$ within the particles in the silica-gel-coated parallel-plate dehumidifier, was in error. In this case, parts of the particles may be blocked by adhesive. Since the predictions of this version of the solid-side-resistance model do not appear promising for small-particle coated silica-gel parallel-plate geometry and the computer cost is relatively high to obtain predictions using this model, we did not use this version of the solid-side-resistance model for further comparison. A model based on the same principles of this solid-side-resistance model without any symmetrical diffusion within the particles is proposed in Section 7.0 for future analysis.

Predictions using the lumped-capacitance model shown in Figures 6-1 to 6-4 were obtained using an $\alpha$ of 1.53 (Le eff of 1.3) based on a formula suggested by Biswas et al. [9]. The predictions are similar to the experimental results. Although there are fluctuations in the inlet and thus outlet conditions of the experimental results and the model does not account for these fluctuations, we can say that the predictions for the adsorption cases (Figures 6-1 and 6-3) agree better with experimental results than the desorption case predictions (Figures 6-2 and 6-4). This behavior has been observed by other investigators $[1,14]$ and may be attributed to the presence of a dynamic hysteresis in the adsorption/desorption characteristics of silica gel.

From the desorption cases it is obvious that the predicted outlet humidity ratio is initially higher than experimental results, and later it is lower than the experimental outlet humidity and also reaches the inlet humidity faster. This means that initially the model predicts a higher desorption rate 
and capacity, but later it predicts a lower capacity. These predictions can result from using inappropriate choices of the equilibrium isotherm equation and effective amount of desiccant.

The predicted outlet air temperature is always higher than the experimental results and reaches inlet air temperature faster. This can be due to several factors: lower heat of adsorption in the model, dependence of heat capacity to temperature, lower equilibrium capacity assumed in the model, heat loss from the test section, and that initially the inlet air temperature in the model is assumed to be higher than the experimental inlet air temperature. Parametric studies of heat of adsorption, equilibrium capacity, and overall mass transfer coefficient need to be done to investigate their effect for improving the predictions. Reducing the fluctuations in the inlet air condition also improves the comparisons.

Figure 6-5 shows the variation of the friction factor versus the Reynolds number. Measured friction factor (Eq. 5-38) is shown to be in good agreement with the prediction (Eq. 5-34), which is based on the assumption of a fully developed laminar flow.

The measured pressure drops across the dehumidifier are within $15 \%$ of the predicted pressure drops, as can be seen from Figure 6-6 and Table 6-2. The predicted values (Eq. 5-39) were obtained based on the average air gap of the passages. Although the variation in actual air gap of the passages is small, the pressure drop variation is larger since the pressure drop is inversely proportional to the third power of the air gap $\Delta \mathrm{P} \propto \mathrm{X}_{\mathrm{gap}}^{-3}$. Also some of the longer particles can partially deform the flow causing flow separation and

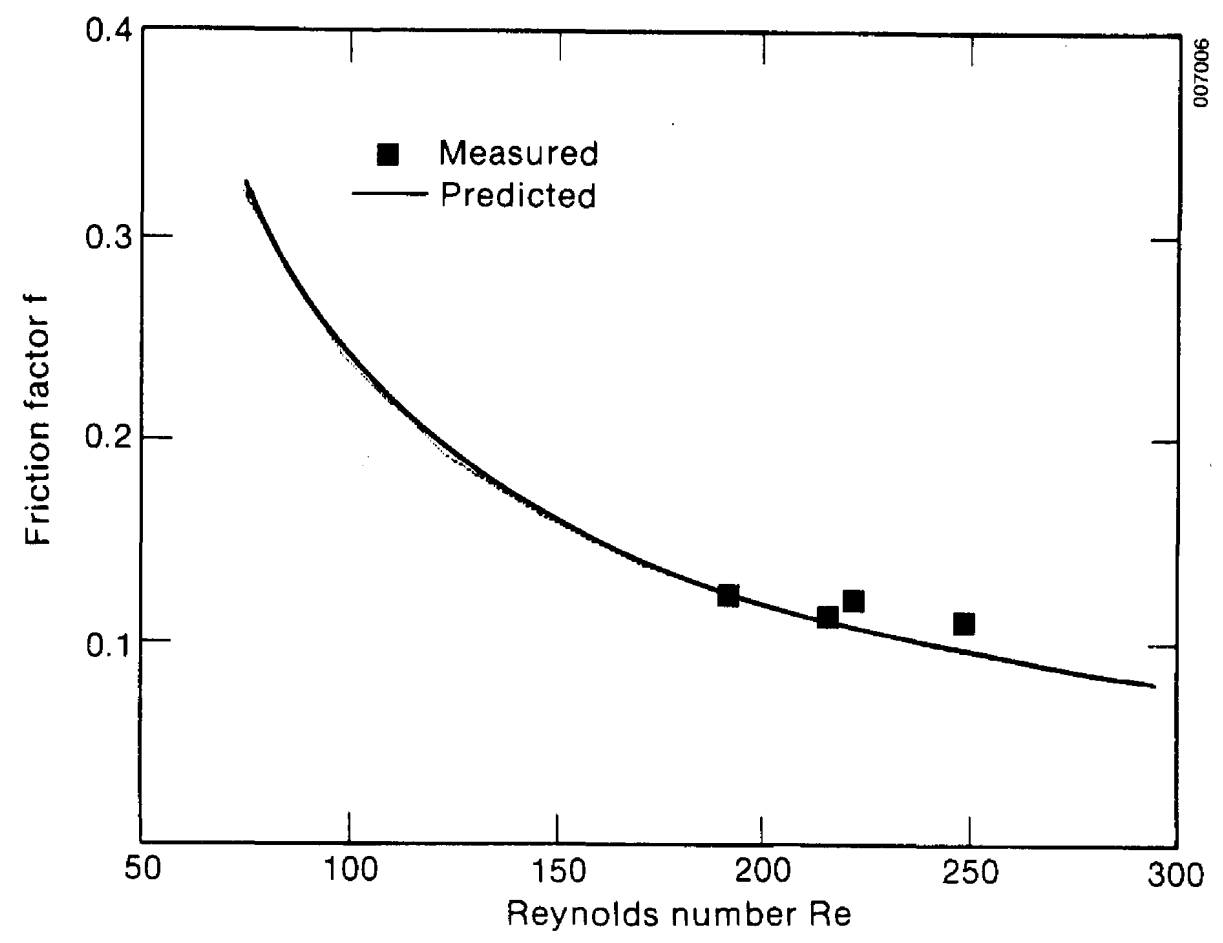

Figure 6-5. Friction Factor Versus Reynolds Number--Measured and Predicted 
increase in pressure drop. Under these circumstances, the $15 \%$ difference is reasonable.

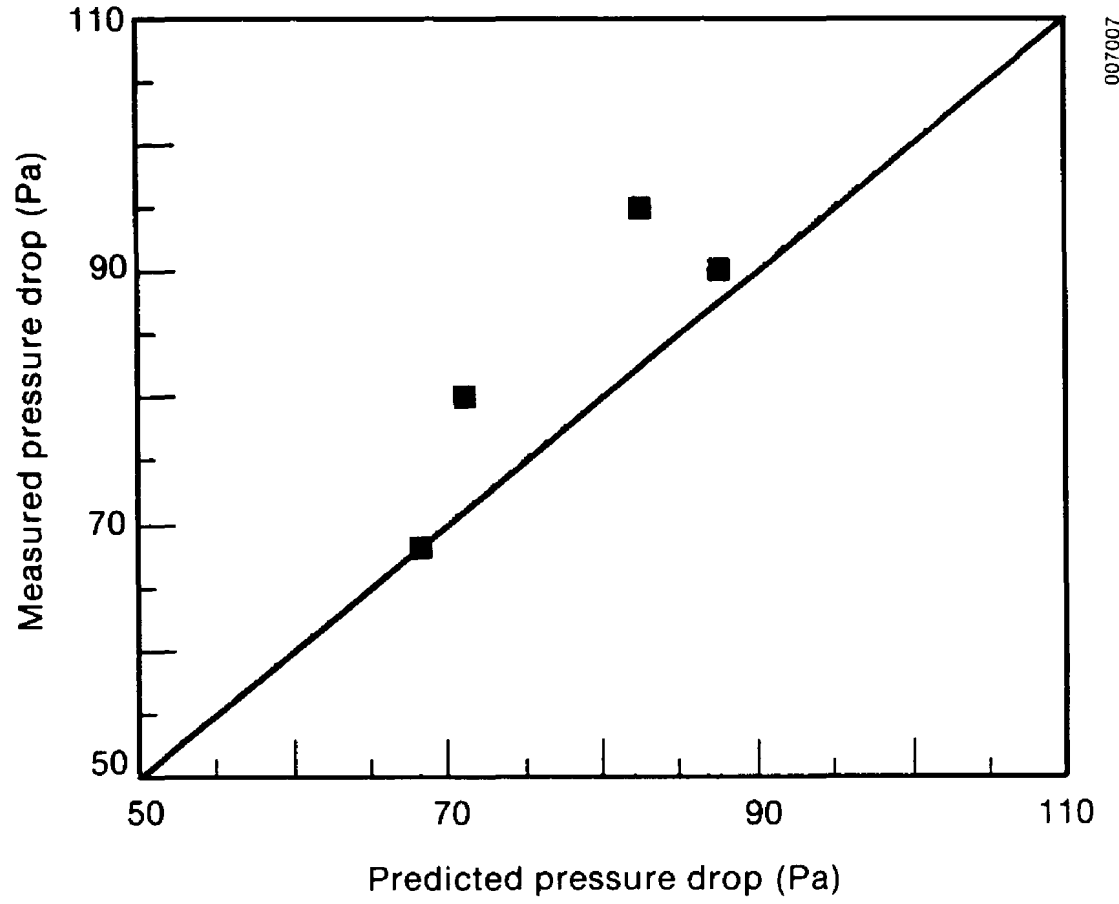

Figure 6-6. Measured versus Predicted Pressure Drop

Table 6-2. Pressure Drop Results

\begin{tabular}{cccccc}
\hline Run No. & $\dot{\mathrm{m}}_{\mathrm{G}}(\mathrm{g} / \mathrm{s})$ & $\mathrm{Re}$ & $\begin{array}{c}\Delta \mathrm{P}_{\text {exp }} \\
(\mathrm{Pa})\end{array}$ & $\begin{array}{c}\Delta \mathrm{P}_{\mathrm{pre}} \\
(\mathrm{Pa})\end{array}$ & $\begin{array}{c}\text { Difference } \\
(\%)\end{array}$ \\
\hline 1 & 20.5 & 248.7 & 95 & 82.6 & 14.9 \\
3 & 18.9 & 215.4 & 90 & 87.4 & 3.0 \\
4 & 18.1 & 221.6 & 80 & 71.1 & 12.5 \\
5 & 16.2 & 192.0 & 68 & 68.2 & -0.2 \\
\hline
\end{tabular}




\subsection{CONCLUSIONS AND FUTURE WORK}

A single-blow test facility for obtaining adiabatic transient response of desiccant dehumidifiers was designed and fabricated. A silica-gel parallelplate dehumidifier with highly uniform passages was designed and fabricated as the first article for testing in this facility. A limited number of adiabatic single-blow experiments were performed and the transient heat and mass transfer data were compared with the predictions of two models in the DESICCANT program that was originally developed for analyzing packed beds. The predictions using the lumped-capacitance model agreed better with the experimental results than the model with solid-side resistance. This result was attributed to poor assumption of symmetrical diffusion in partially blocked silica gel particles. The comparisons between the predictions of the lumped-capacitance model and experimental data are generally satisfactory, within $10 \%$ for adsorption and $30 \%$ for desorption. They are better for adsorption cases than desorption cases as observed by previous investigators. Pressure drops across the parallel-plate dehumidifier were measured and were within $15 \%$ of the predicted pressure drops.

The results obtained in this test facility can be used to design dehumidifiers in two ways:

- by comparing the transient performance of various geometric/material combinations and then recommending combinations that have greater potential to provide efficient dehumidifiers, and

- by providing the data for validating the heat and mass transfer models of dehumidifiers and then using these validated models to design more efficient dehumidifiers.

The inlet humidity level was not uniform when the ambient air was humidified by injecting steam from the boiler to the process air. The fluctuations were attributed to fluctuations in the steam supply pressure in the boiler and poor control of steam injection rate by the controller valve. These activities and conclusions were performed in a FY 1984 project. In FY 1985, we continued our efforts to improve the single-blow test facility. These efforts are documented in a forthcoming report [21]. The test article needs to be modified by changing the air gap of the passages and particle size of the desiccant for further testing. In FY 1985 we planned to test a promising geometry (staggered parallel strip) to evaluate its potential as an advanced geometry for desiccant dehumidifiers.

To improve the solid-side-resistance model we can assume that the silica gel layers on the polyester tapes act as slabs of solid with a thickness of $d$ and then we solve the diffusion equation in these slabs rather than solving the

*With the efforts in FY 1985 we were successful in obtaining a more uniform inlet humidity ratio by solving the humidity control problem. After resolving this problem we obtained transient response of the parallel-plate test article by performing experiments at different air flow rates and inlet and initial conditions. 
diffusion equation in spherical particles. Then the only equation that needs to be modified is Eq. 6-12 which becomes

$$
\frac{\partial W}{\partial t^{*}}=\frac{\partial}{\partial y^{*}}\left(D^{*} \frac{\partial W}{\partial y^{* *}}\right),
$$

with boundary conditions:

at the wall

$$
\left.\frac{\partial W}{\partial y^{*}}\right|_{y^{*}=0}=0,
$$

at the surface of the particles adjacent to the air gap

$$
-\left.\beta \frac{\partial W}{\partial y^{*}}\right|_{y^{*}=1}=m_{1, s}-m_{1, e} \text {. }
$$

The dimensionless parameters in the above set of equations are

$$
y^{*}=\frac{y}{d_{p}}, t^{*}=\frac{t}{\tau}, D^{*}=\frac{D_{\tau}}{d_{p}^{2}}, \beta=\frac{\rho_{p} D}{k_{G} d_{p}} .
$$

Other governing equations remain the same. Solutions of this model need to be obtained numerically and compared with the experimental results so that the model can be improved and validated.

In FY 1985, we planned to apply the method of moments $[27,28]$ to the transient heat and mass transfer data to directly obtain heat and mass transfer coefficients. Transient heat transfer tests for heat exchangers have been interpreted using the first statistical moment of temperature distribution to estimate the matrix heat capacity and the second moment to estimate the number of heat transfer units and thus the heat transfer coefficient [27]. The same method can be applied to transient heat and mass transfer data by using combined potentials. Each combined potential satisfies equations analogous to those for heat transfer alone and has a characteristic wave speed. We expect that this method will estimate the heat and mass transfer coefficients from the transient data and eliminate some of the subjectivity used in the traditional method of matching the experimental transient data with the predictions. 


\subsection{REFERENCES}

1. Barlow, R. S., Analysis of the Adsorption Process of Desiccant Cooling Systems - A Psuedo-Steady-State Model for Coupled Heat and Mass Transfer, SERI/TR-631-1330, Golden, CO: Solar Energy Research Institute, 1982.

2. Booz-Allen, and Hamilton, Evaluation of Residential and Commercial Solar/Gas Heating and Cooling Technologies, GRI-70/0105, Chicago, IL: Gas Research Institute, 1981.

3. Scholten, W. B. and J. H. Morehouse, Active Program Research Requirements: Final Report, McLean, VA: science Applications, Inc., 1983.

4. Jurinak, J. J., Open Cycle Desiccant Cooling: Component Models and System Simulations, Ph.D. Thesis, Madison, WI: University of Wisconsin, Solar Energy Laboratory, August 1982.

5. Nienberg, J. W., "Modeling of Desiccant Performance for Solar-DesiccantEvaporative Cooling Systems," M.S. Thesis, Los Angeles, CA: University of California, 1977.

6. Pla-Barby, F. E., G. C. Vliet, and R. L. Panton, "Performance of Rotary Bed Silica Gel Solid Desiccant Dryers," ASME 78-HT-36, 1978.

7. Gidaspow, D., Z. Lavan, M. Onischak, and S. Perkari, "Development of a Solar Desiccant Dehumidifier," Proceedings of the 3rd Workshop on the Use of Solar Energy for the Cooling of Buildings, pp. 83-89, 1978 .

8. Wurm J., Kinart, Rush, T. S. Zawacki, R. S. Macriss, Solar-MEC ${ }^{\mathrm{C}}$ Development Program - Annual Program Report, Chicago, IL: c $\overline{00-4495-15}$, Institute of Gas Technology, 1979.

9. Biswas, P., S. Kim, and A. F. Mills, "A Compact Low-Pressure Drop Desiccant Bed for Solar Air Conditioning Application: Analysis and Design," Journal of Solar Energy Engineering, Vol. 106, 1984, pp. 153158 .

10. Schlepp, D. and R. Barlow, Performance of SERI Parallel-Passage Dehumidifier, SERI/TR-252-1951, Golden, CO: Solar Energy Research Institute, September 1984.

11. Schultz, K. J. and D. Schlepp, Experimental Test Plan for Cyclic Testing of Parllel Passage Rotary Desiccant Dehumidifers, Draft Report prepared for the U. S. Department of Energy, April 1984.

12. Lavan, Z., V. Worek, and J. Monnier, "Cooled Bed Solar-Powered Air Conditioning," presented at the 16th IECEC, Atlanta, GA, 1981. 
13. Gunderson, M. E., Development of Solar Desiccant Dehumidifiers, Report on Contract EG-77-C-03-1591, Torrance, CA: AiResearch Manufacturing Company of California, 1978.

14. Pesaran, A. A., "Moisture Transport in Silica Gel Particle Beds," Ph.D. Dissertation, Los Angeles, CA: University of California, 1983.

15. Barlow, R., An Assessment of Dehumidifier Geometries for Desiccant Cooling Systems, SERI/TR-252-1529, Golden, CO: Solar Energy Research Institute, June 1983.

16. Kim, S., "Development of a Laminar Flow Desiccant Bed for Solar Air Conditioning Application," Masters Thesis, Los Angeles, Ca: University of California, 1981.

17. Biswas, P., "An Experimental Study of the Performance of a Laminar Flow Silica Gel Desiccant Packing Suitable for Solar Air Conditioning Application," Masters Thesis, Los Angeles, CA: University of California, 1981.

18. Ambrose, C. W., I. L. Maclain-cross, and E. B. Robsen, The Use of Rotary Heat Regenerative Heat Exchanger for the Conservation of Energy in Buildings. Final Report Project 109. National Energy Research. Development and Government Committee. Australian Government, Canberra, 1983.

19. Kutscher, C. F. and R. S. Barlow, Dynamic Performance of Packed-Bed Dehumidifiers: Experimental Results from the SERI Desiccant Test Laboratory, SERI/TR-252-1429, Golden, CO: Solar Energy Research Institute, August 1982.

20. Maclaine-cross, I. L. "A Theory of Combined Heat and Mass Transfer in Regenerators," Ph.D. Thesis, Australia: Monasch University, 1974.

21. Pesaran, A. A., I. L. Maclaine-cross, and E. Van den Bulck, Measurements on Promising Desiccant Dehumidifier Materials and Geometries, SERI/TR252-2898, Golden, CO: Solar Energy Research Institute, forthcoming.

22. Schultz, K. J., SERI Desiccant Cooling Facility: Status Report, SERI/TR252-2718, Golden, CO: Solar Energy Research Institute, 1986.

23. Maclaine-cross, I. L. and C. W. Ambrose, "Predicted and Measured Pressure Drop in Parallel Plate Rotary Regenerators," Journal of Fluid Engineering, Vol. 102, March 1980, pp. 59-63.

24. Cornish, R. J., "Flow in a Pipe of Rectangular Cross-Section," Proceedings of the Royal Society, Vol. Al20, 1928, pp. 691-700.

25. Kays, W. M. and A. L. London, Compact Heat Exchangers, New York, NY: McGraw-Hill Book Co., 1964.

26. Maclaine-cross, I. L., Personal Communication, University of New South Wales, Australia, Feb. 1985. 
27. Jeffreson, C. P., "Dynamic Testing--a Unification," Chemical Engineering Science, Vol. 25, 1970, pp. 1319-1329.

28. Ruthven, D. M., Principles of Adsorption and Adsorption Processes, New York: John Wiley and Sons, Inc., pp. 242-244, 1984. 


\section{APPENDIX A}

\section{LISTING OF PROGRAMS}

This appendix 1 ists the data acquisition program (DAP) and the program that analyzes the raw data and plots them in outlet air conditions as a function time (PLOT). Both programs are written in BASIC for the HP9845A. 


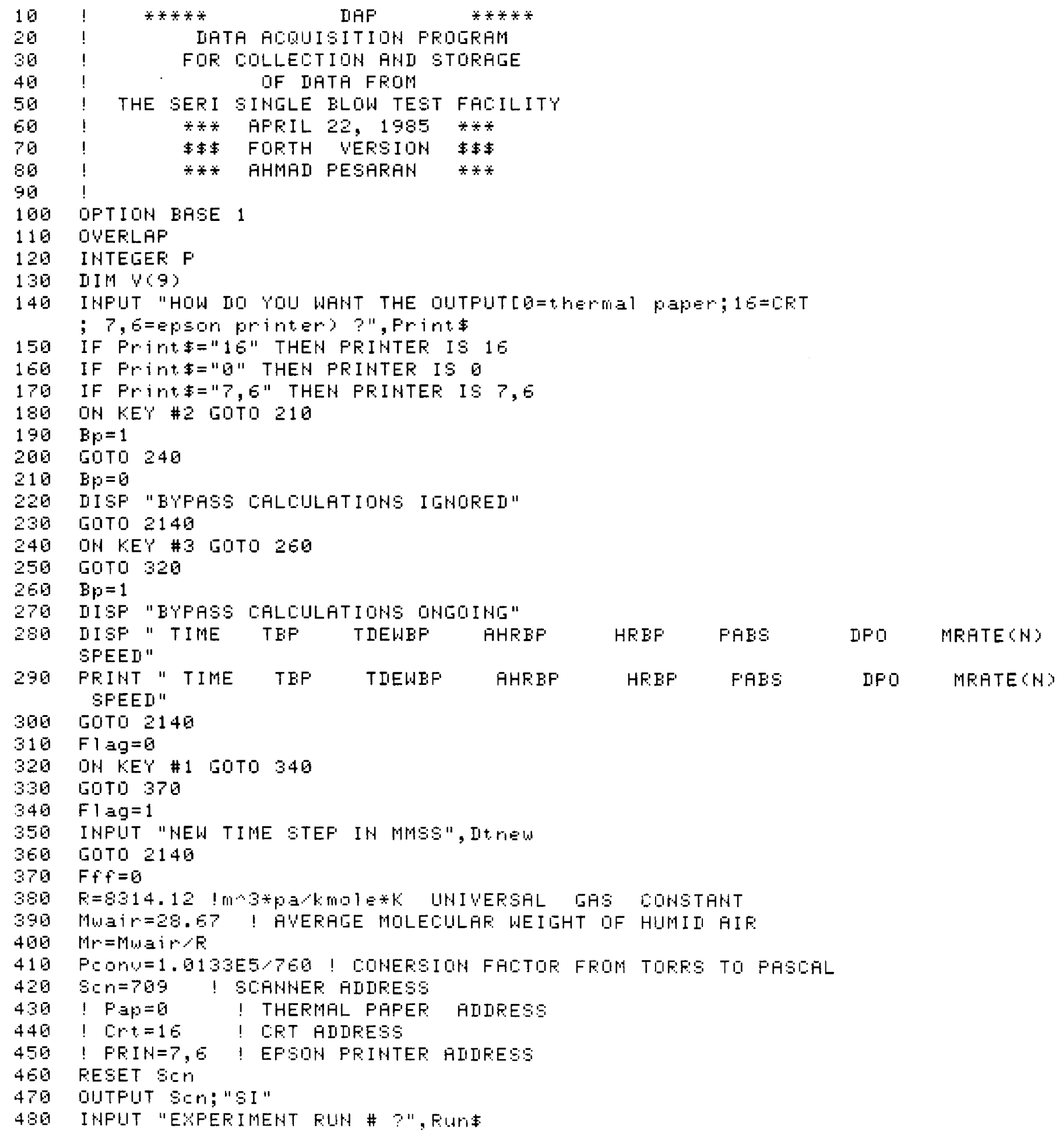




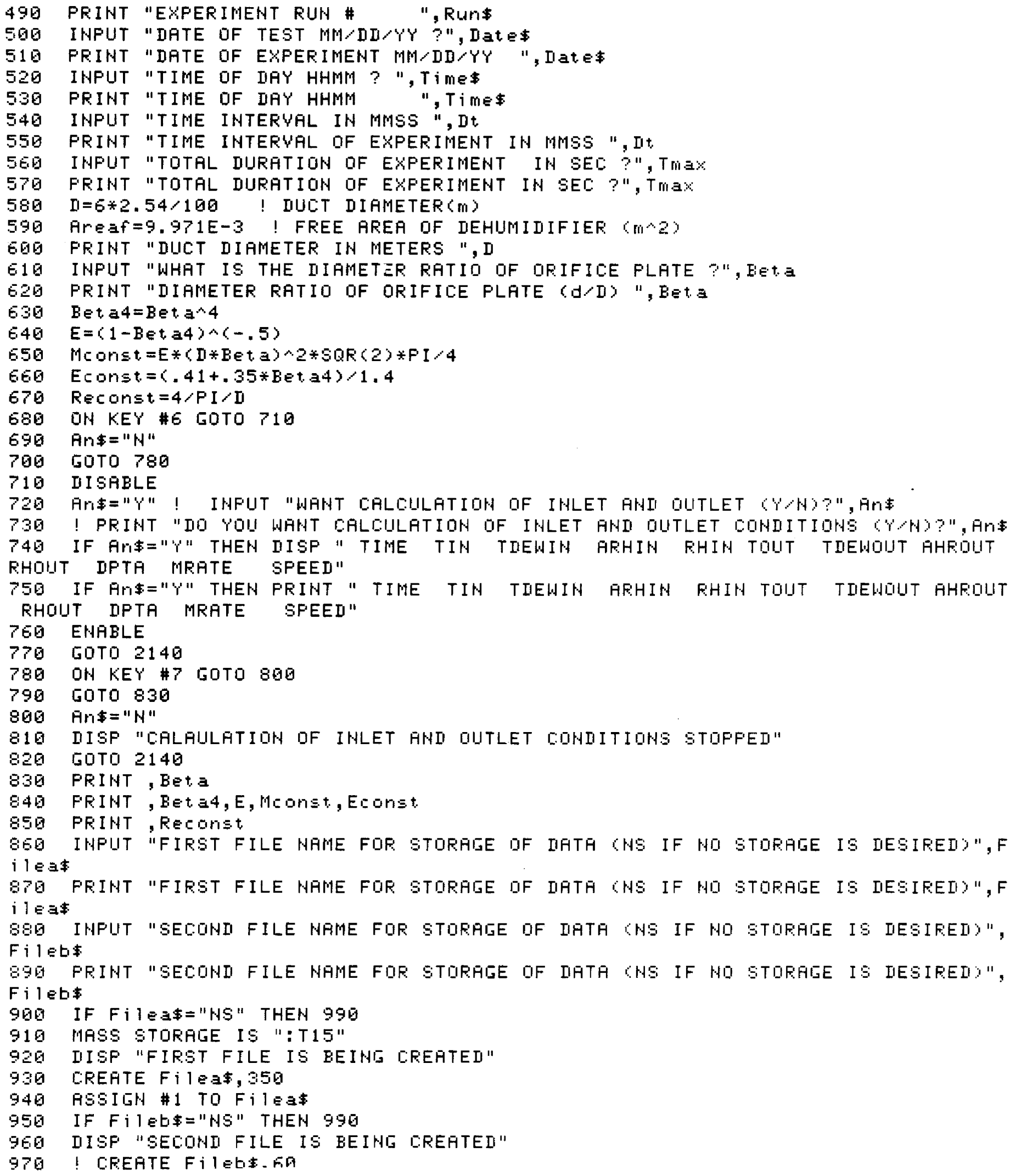




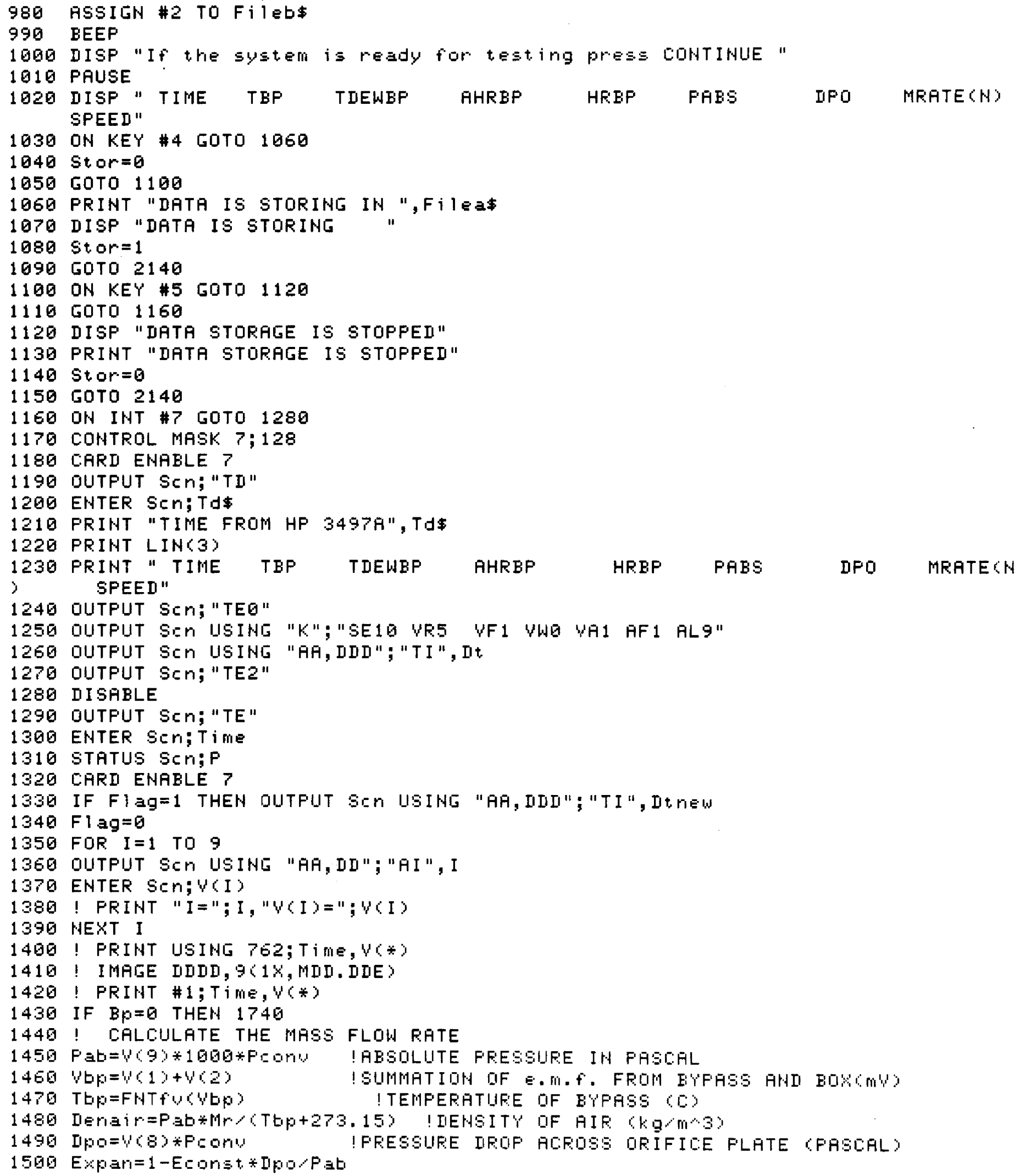




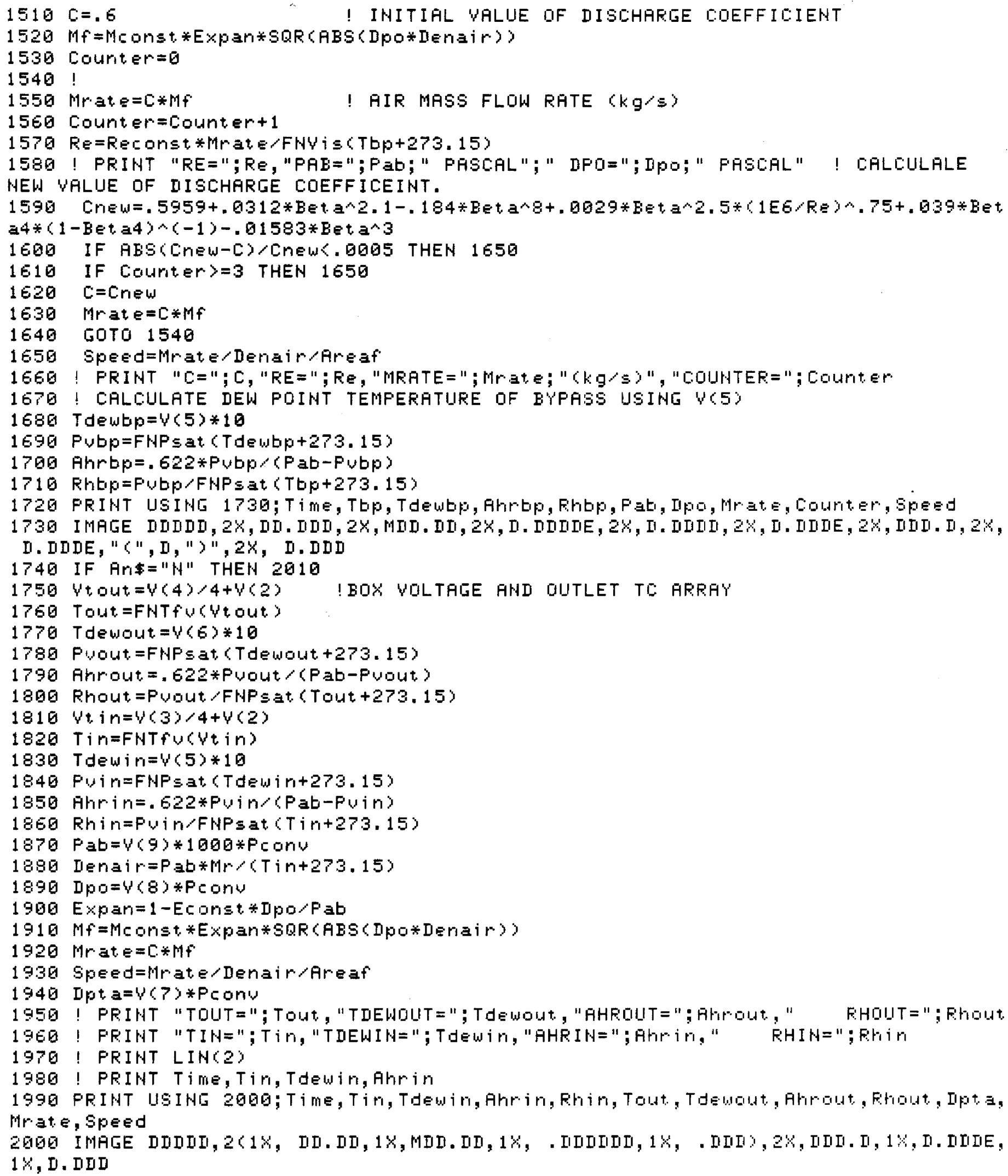




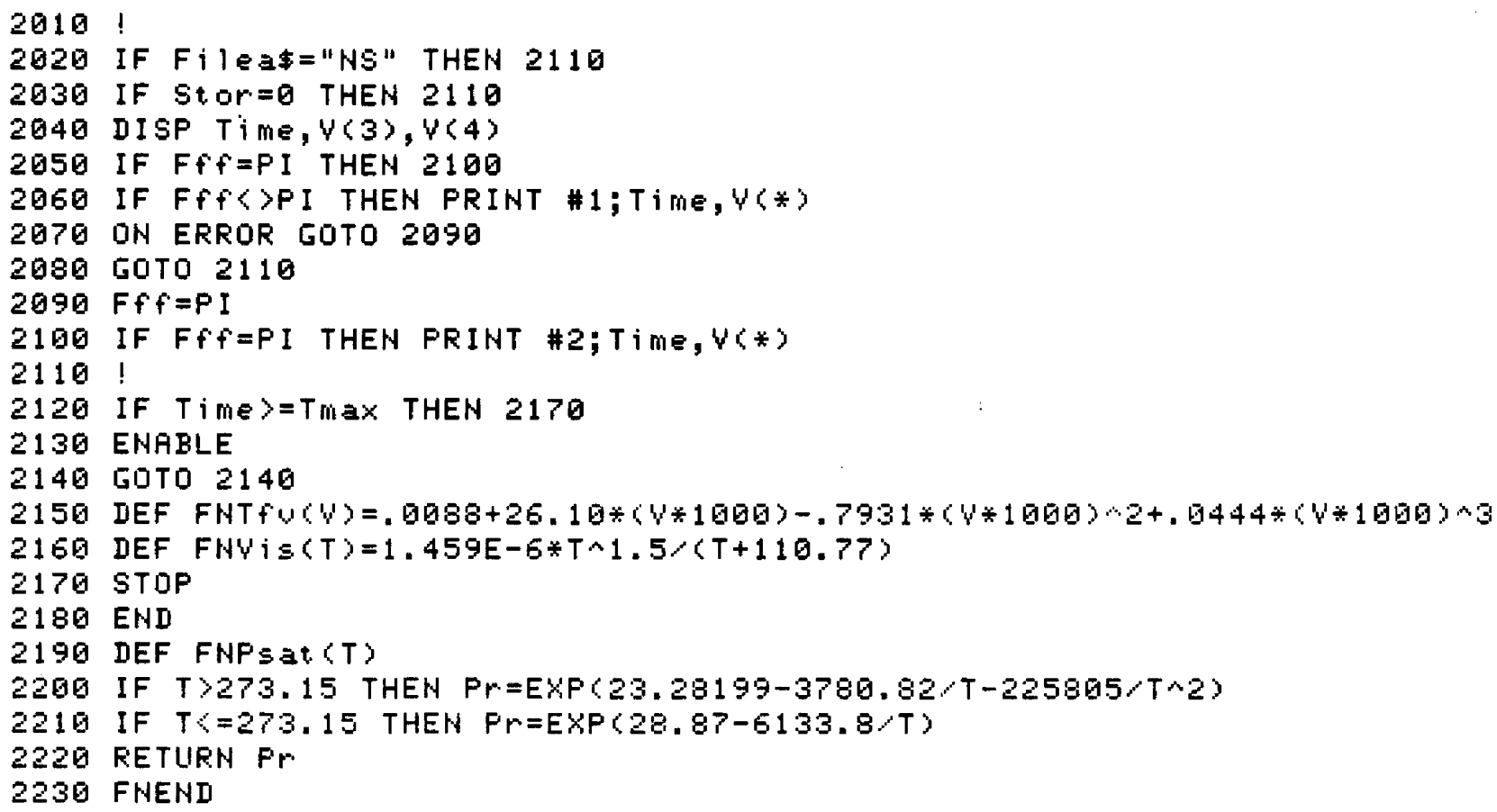




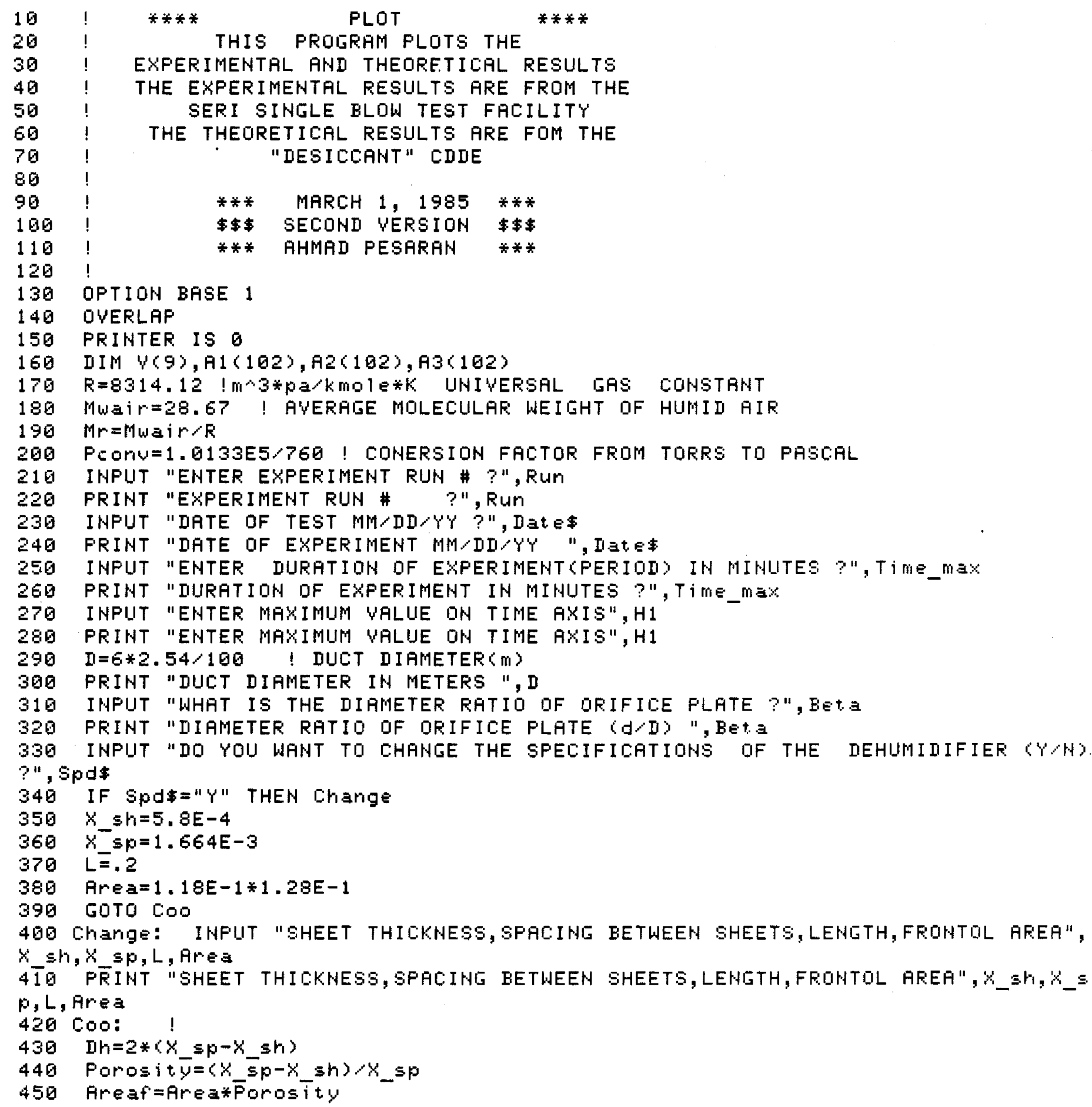




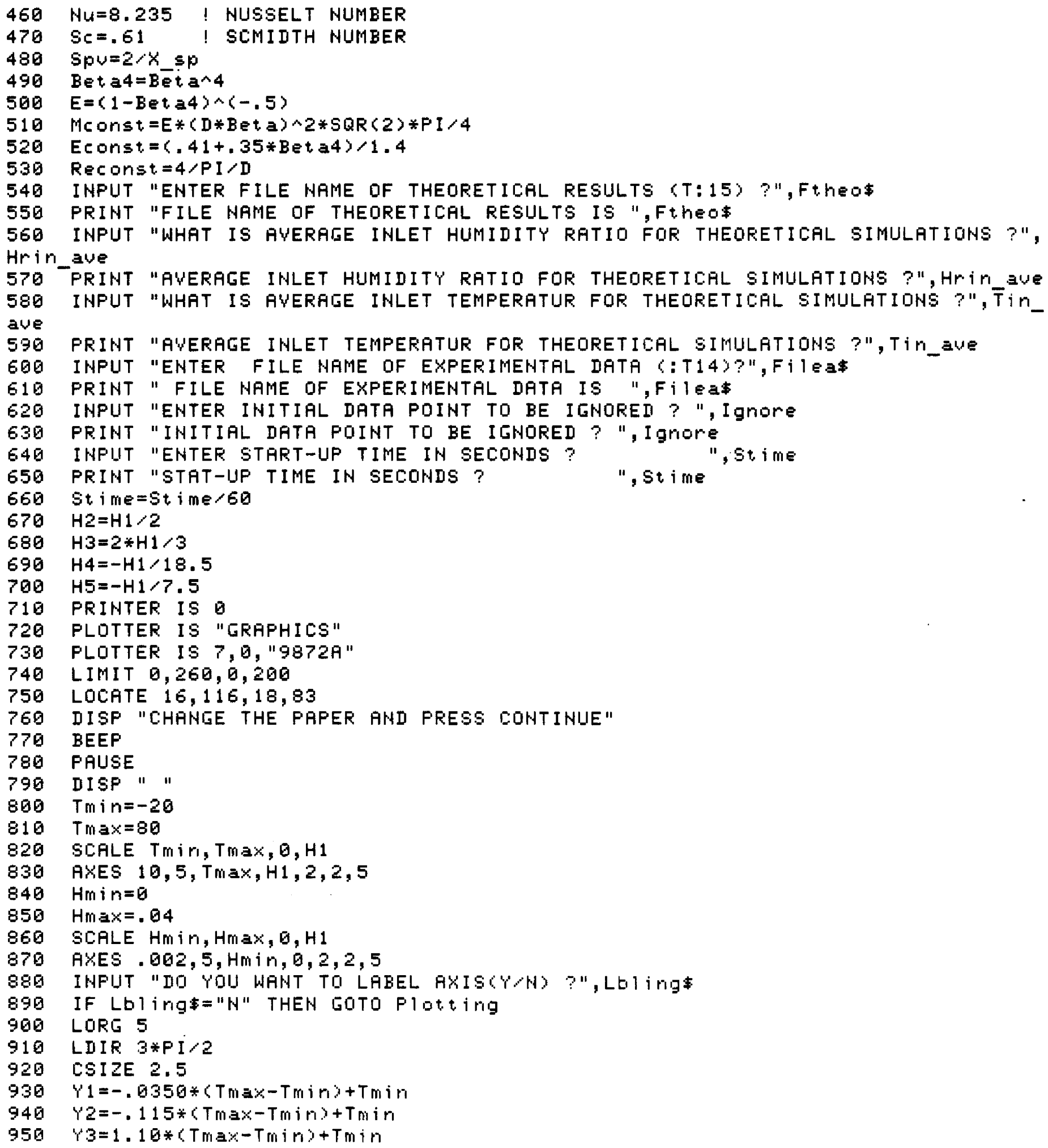

PRINT "AVERAGE INLET TEMPERATUR FDR THEORETICAL SIMULATIOHS ?",Tin_aUE INPUT "ENTER FILE NAME OF EXPERIMENTAL DATA ¿:T14)?",Filea\$ 


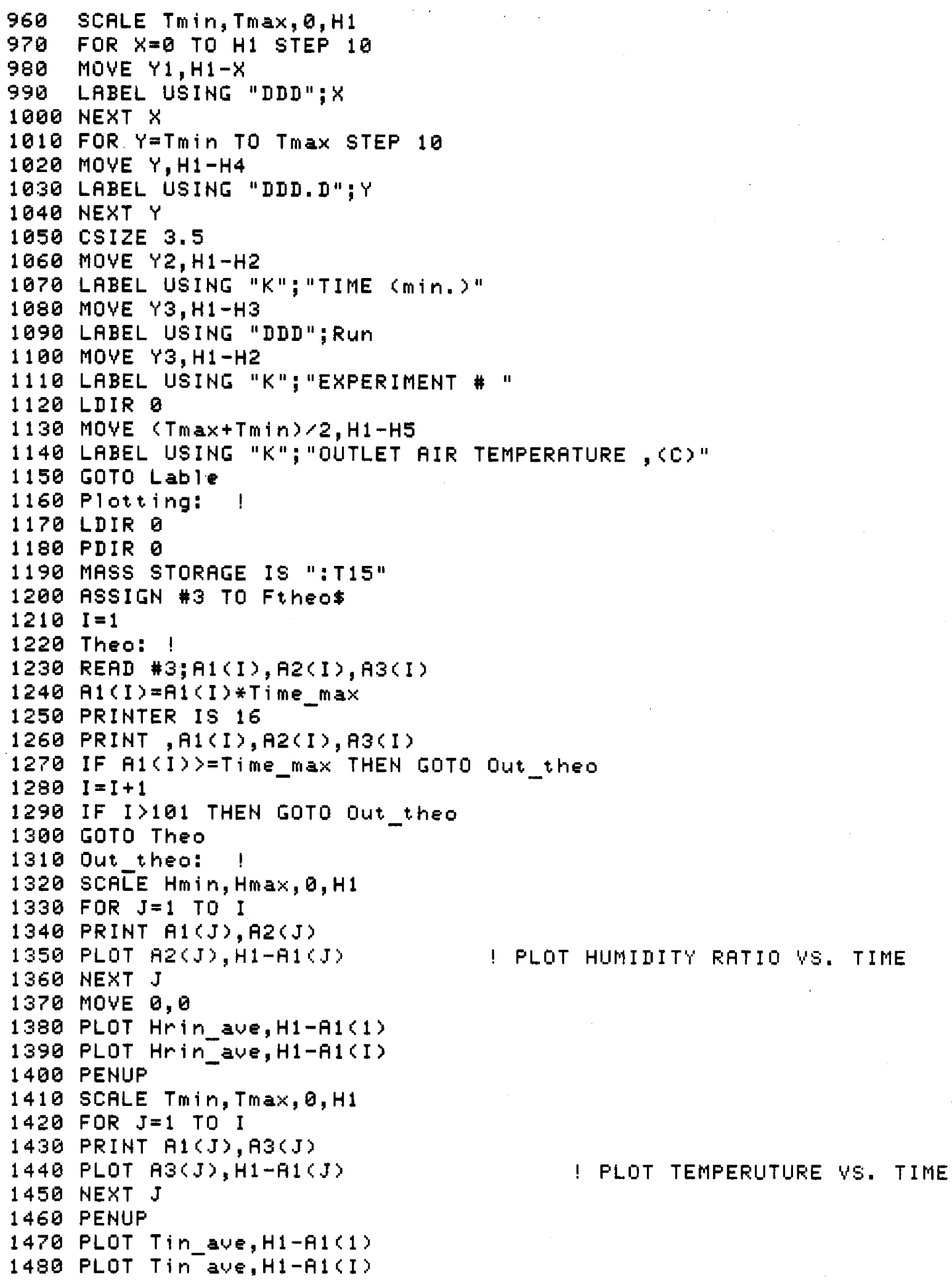




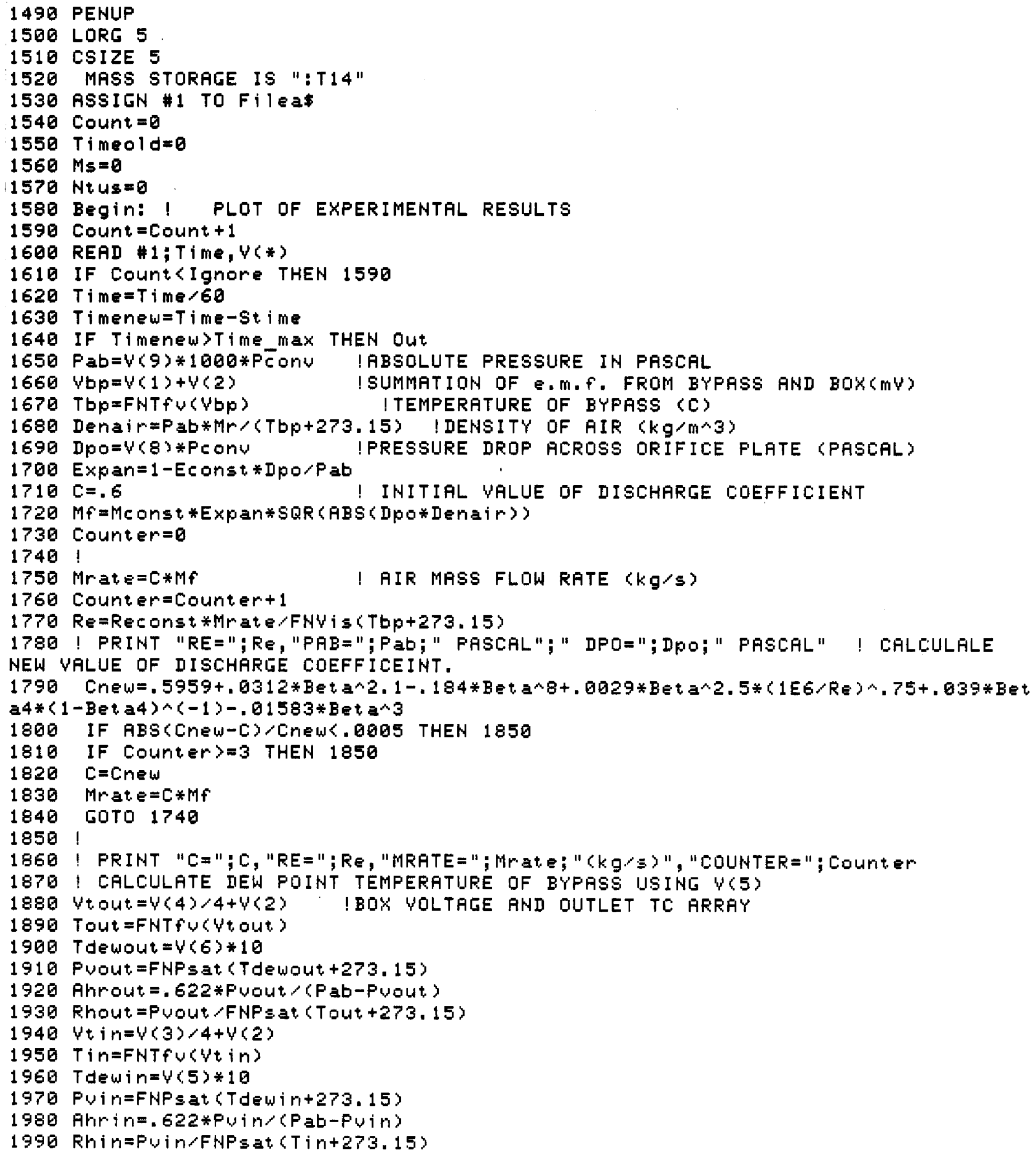




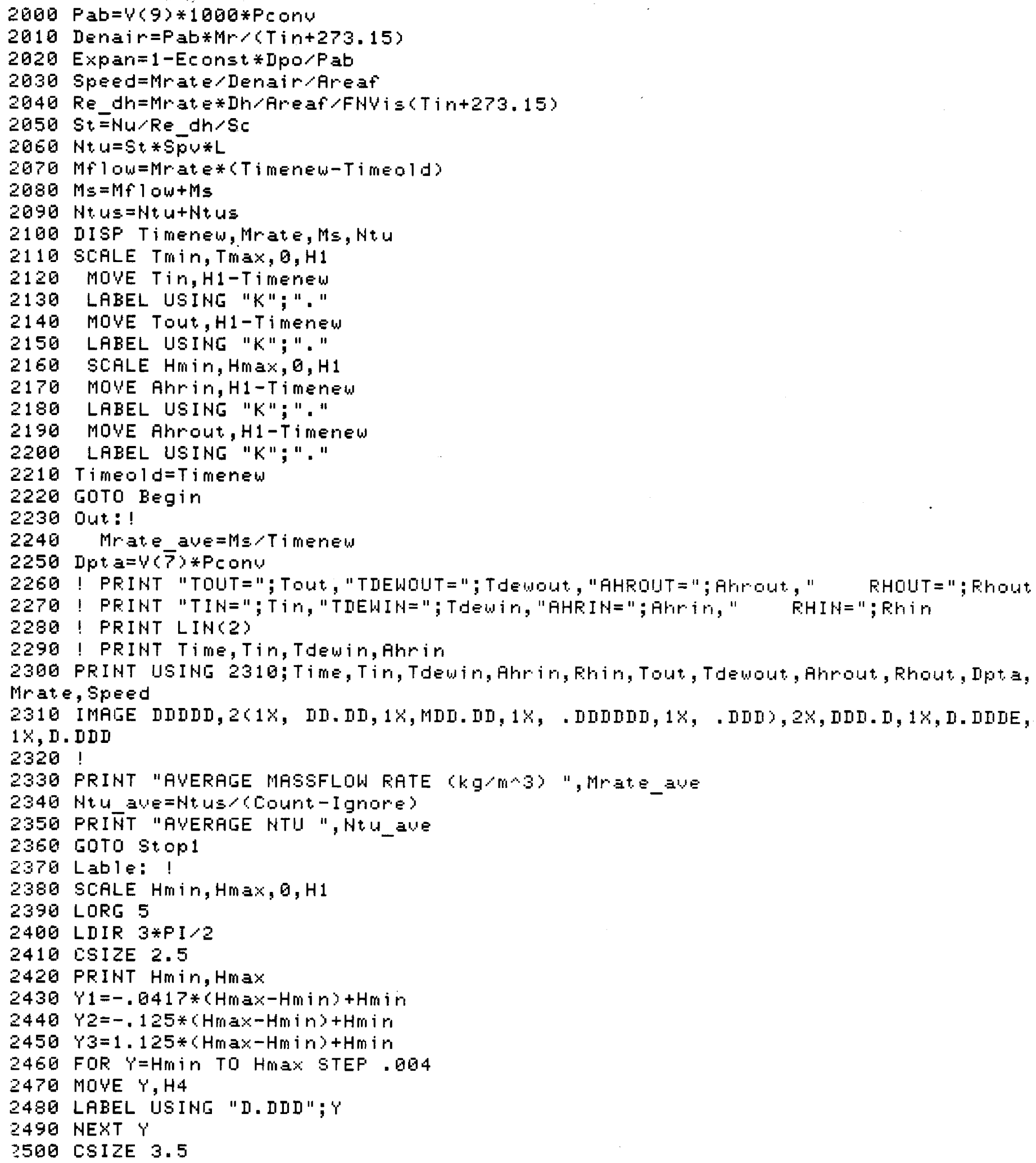




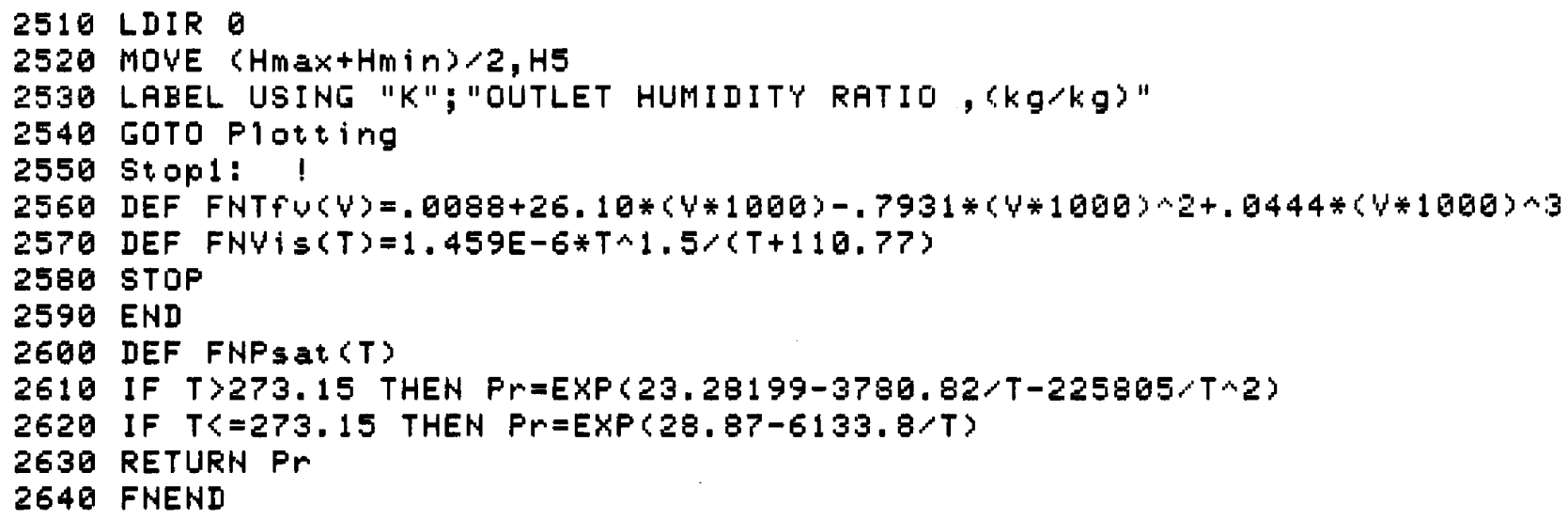


William M. Anderson Anderson Consulting 7605 E. Windlawn Way

Parker, CO 80134

Carl Bergt

Trane Systems Engineering Co. 6200 Troup Highway

Tyler, TX 75711

Kennard L. Bowlen

Cargocaire Engineering Corp. 79 Monroe St.

Amesbury, MA 01913

Glen Chinery

Tennessee Valley Authority

217 Power Board B1dg

Chattanooga, TN 37401

James Coellner, Director R\&E

American Solar King Corp.

700 Loop 340 South

Waco, TX 76710

Barry Cohen

Thermal Products Division

ThermoElectron Corporation

45 First Avenue

Wal tham, MA 02154

Kirk Collier, Ph.D.

Everscope, Inc.

4886 W. Port Au Prince

Glendale, AZ 85306

Keith Davidson

Gas Research Institute

8600 West Bryn Mawr Avenue

Chicago, IL 60631

Jim Hill, Ph.D.

National Bureau of Standards

Technology B-148

Washington, D.C. 20585

Michael Epstein

Fauske \& Associates, Inc. 162070 West 83rd Street

Burr Ridge, IL 60521

\author{
Phillip Fairey \\ Florida Solar Energy Center \\ 300 State Road, 401 \\ Cape Canaveral, FL 32920 \\ Stephen D. Fitch \\ Bry-Air \\ P. O. Box 795 \\ Sunbury, OH 43074 \\ Anthony Fraioli, Ph.D. \\ Argonne National Laboratory \\ 9700 South Cass Avenue \\ Argonne, IL 60439 \\ John Goldsmith \\ U.S. Department of Energy \\ Route CE-311, Room 5H065 \\ 1000 Independence Ave., S.W. \\ Washington, DC 20585 \\ Anthony Hines, Ph.D. \\ College of Engineering \\ Oklahoma State University \\ Stillwater, OK 74078 \\ Robert Jones \\ Los Alamos National Laboratory \\ P.0. Box 1663 \\ Mail Stop H577 \\ Los Alamos, NM 87545 \\ K. LaPorta \\ SEIA \\ 1156 15th St., N.W., Suite 520 \\ Washington, DC 20005 \\ Zalman Lavan, Ph.D. \\ Illinois Institute of Technology \\ Department of Mechanical Engineering \\ Illinois Institute of Technology \\ Center \\ Chicago, IL 60616 \\ Robert LeChevalier \\ U.S. Department of Energy \\ San Erancisco Operations Office \\ 1333 Broadway \\ Oakland, CA 94612
}


George 0. G. Lof, Ph.D. Colorado State University

Solar Energy Applications Laboratory

Fort Collins, CO 80523

Ian Maclaine-cross, Ph.D.

University of New South Wales

School of Mechanical and Industrial Engineering

P.0. Box 1

Kensington, NSW 2033 Australia

John Mitche11, Ph.D.

University of Wisconsin-Madison

Engineering Research Building

1500 Johnson Drive

Madison, WI 53706

Jeff Morehouse

Department of Mechanical Engineering

University of South Carolina

Columbia, SC 29208

Frederick Morse, Ph.D.

U.S. Department of Energy

Route CE-31, Room 5H-095

1000 Independence Ave., S.W.

Washington, DC 20585

Yves 0. Parent

Res. Eng.

Industrial Chemicals Research

Davison Chemical Division

W. R. Grace \& Co.

Washington Research Center

7379 Route 32

Columbia, MD 21044

David Pellish

Solar Buildings Technology Division

office of Solar Heat Technology

U.S. Department of Energy

Forrestal Building, Room 5H-041

1000 Independence Ave., S.W.

Washington, DC 20585

D. M. Ruthven, Ph.D.

University of New Brunswick

P. O. Box 4400

Fredericton, N.B.

Canada E58 $5 \mathrm{~A} 3$
M. Wahlig, Ph.D.

Lawrence Berkeley Laboratories

University of California

1 Cyclotron

Berkeley, CA 94720

Alex Willman

ACEC Resource and Management

Foundation

1015 15th Street, N.W.

Washington, DC 20005

Byard Wood, Ph.D.

Department of Mechanical \& Aerospace

Engineering

Arizona State University

Tempe, AZ 85287 


\begin{tabular}{|c|c|c|c|}
\hline $\begin{array}{c}\text { Document Control } \\
\text { Page }\end{array}$ & \begin{tabular}{|l|} 
1. SERI Report No. \\
SERI/TR-252-2774
\end{tabular} & 2. NTIS Accession No. & 3. Recipient's Accession No. \\
\hline \multirow{2}{*}{\multicolumn{3}{|c|}{$\begin{array}{l}\text { 4. Title and Subtitle } \\
\text { Heat \& Mass Transfer Analysis of a Desiccant } \\
\text { Dehumidifier Matrix }\end{array}$}} & $\begin{array}{l}\text { 5. Publication Date } \\
\text { July } 1986\end{array}$ \\
\hline & & & 6. \\
\hline \multicolumn{3}{|l|}{ 7. Author(s) } & 8. Performing Organization Rept. No. \\
\hline \multicolumn{3}{|c|}{ 9. Performing Organization Name and Address } & 10. Project/Task/Work Unit No. \\
\hline \multicolumn{3}{|c|}{$\begin{array}{l}\text { Solar Energy Research Institute } \\
\text { A Division of Midwest Research Institute } \\
1617 \text { Cole Boulevard } \\
\text { Golden, Colorado } 80401-3393\end{array}$} & $\begin{array}{l}\text { 11. Contract (C) or Grant (G) No. } \\
\text { (C) } \\
\text { (G) }\end{array}$ \\
\hline \multirow{2}{*}{\multicolumn{3}{|c|}{ 12. Sponsoring Organization Name and Address }} & $\begin{array}{l}\text { 13. Type of Report \& Period Covered } \\
\text { Technical Report }\end{array}$ \\
\hline & & & 14. \\
\hline \multicolumn{4}{|l|}{ 15. Supplementary Notes } \\
\hline \multicolumn{4}{|c|}{$\begin{array}{l}\text { 16. Abstract (Limit: } 200 \text { words) } \\
\text { This report documents the SERI Single-Blow Test Facility's design, fabrication, } \\
\text { and testing for characterizing desiccant dehumidifiers for solar cooling } \\
\text { applications. The first test article, a silica-gel parallel-plate dehumidifier. } \\
\text { with highly uniform passages, was designed and fabricated. Transient heat and } \\
\text { mass transfer data and pressure drop data across the dehumidifier were obtained. } \\
\text { Available heat and mass transfer models were extended to the parallel-plate } \\
\text { geometry, and the experimental data were compared with model predictions. } \\
\text { Pressure drop measurements were also compared with model predictions of the fully } \\
\text { developed laminar flow theory. The comparisons between the lumped-capacitance } \\
\text { model and the experimental data were satisfactory. The pressure drop data com- } \\
\text { pared satifactorily with the theory (within 15\%). A solid-side resistance mode1 } \\
\text { that is more detailed and does not assume symmetrical diffusion in particles } \\
\text { was recommended for performance. This study has increased our understanding } \\
\text { of the heat and mass transfer in silica gel parallel-plate dehumidifiers. }\end{array}$} \\
\hline \multicolumn{4}{|c|}{$\begin{array}{l}\text { 17. Document Analysis } \\
\text { a. Descriptors Dehumidifiers } \\
\text { Silica Ge1; Testing } \\
\text { b. Identifiers/Open-Ended Terms }\end{array}$} \\
\hline \multicolumn{3}{|l|}{ c. UC Categories } & $59 a$ \\
\hline \multirow{2}{*}{\multicolumn{3}{|c|}{$\begin{array}{l}\text { National Technical Information Service } \\
\text { U.S. Department of Commerce } \\
5285 \text { Port Royal Road } \\
\text { Springfield, Virginia } 22161\end{array}$}} & $\begin{array}{c}\text { 19. No. of Pages } \\
63\end{array}$ \\
\hline & & & $\begin{array}{l}\text { 20. Price } \\
\mathrm{AO} 4\end{array}$ \\
\hline
\end{tabular}

